\title{
Dehydroabietylamine Ureas and Thioureas as Tyrosyl-DNA Phosphodiesterase 1 Inhibitors That Enhance the Antitumor Effect of Temozolomide on Glioblastoma Cells.
}

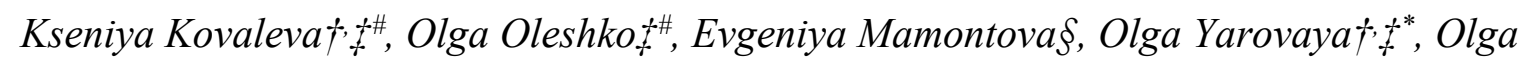
Zakharova§, Alexandra Zakharenko§, Alena Kononovał, Nadezhda Dyrkheeva§, Sergey

Cheresizt, $\perp$, Andrey Pokrovsky $\neq$ Olga Lavrikt, $\S$ and Nariman Salakhutdinov $\neq \neq$

$\dagger$ N. N. Vorozhtsov Novosibirsk Institute of Organic Chemistry, Siberian Branch of the Russian Academy of Sciences, Novosibirsk, 630090, Russian Federation

†Novosibirsk State University, Novosibirsk, 630090, Russian Federation

$\S$ Novosibirsk Institute of Chemical Biology and Fundamental Medicine, Siberian Branch of the Russian Academy of Sciences, Novosibirsk, 630090, Russian Federation

$\perp$ State Scientific Research Institute of Physiology and Basic Medicine, P.O. Box 237, Novosibirsk, 630117, Russian Federation. 


\section{Supporting Information}

1. ${ }^{1} \mathrm{H}$ NMR and ${ }^{13} \mathrm{C}$ NMR spectra of compounds 1-12

2. IR spectra of compounds 1-12

3. High Resolution Mass Spectra of Compounds 1-12 
1. ${ }^{1} \mathrm{H}$ NMR and ${ }^{13} \mathrm{C}$ NMR spectra of compounds $1-12$

1.1. Compound 1

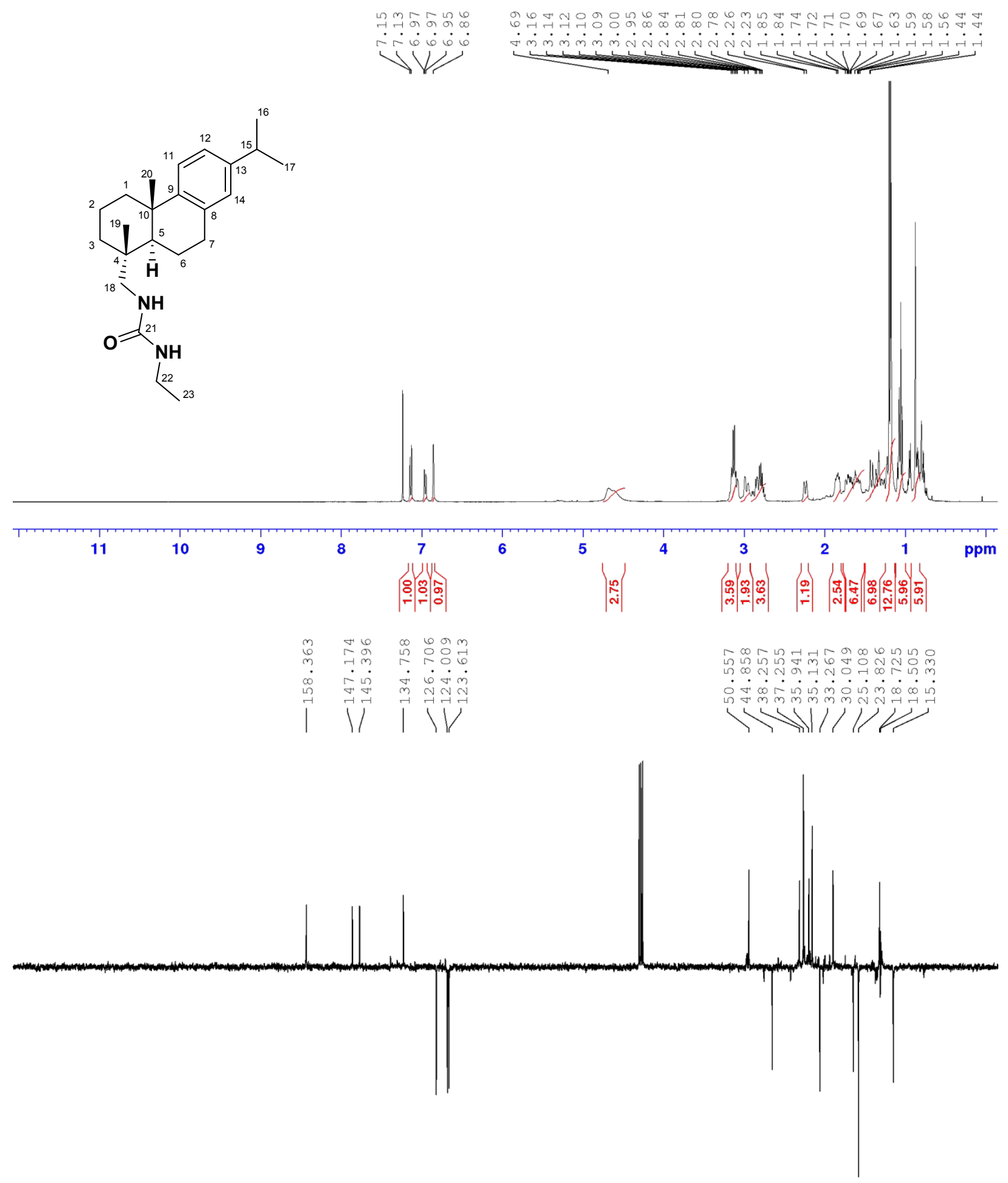

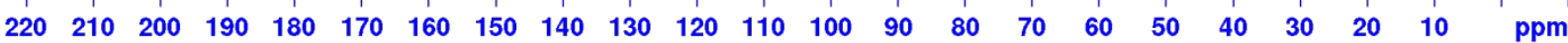




\subsection{Compound 2}

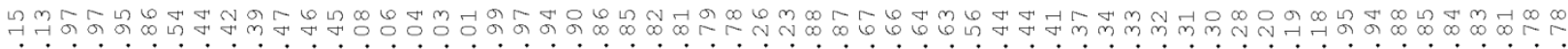

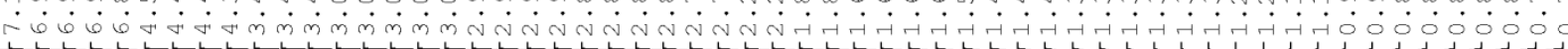
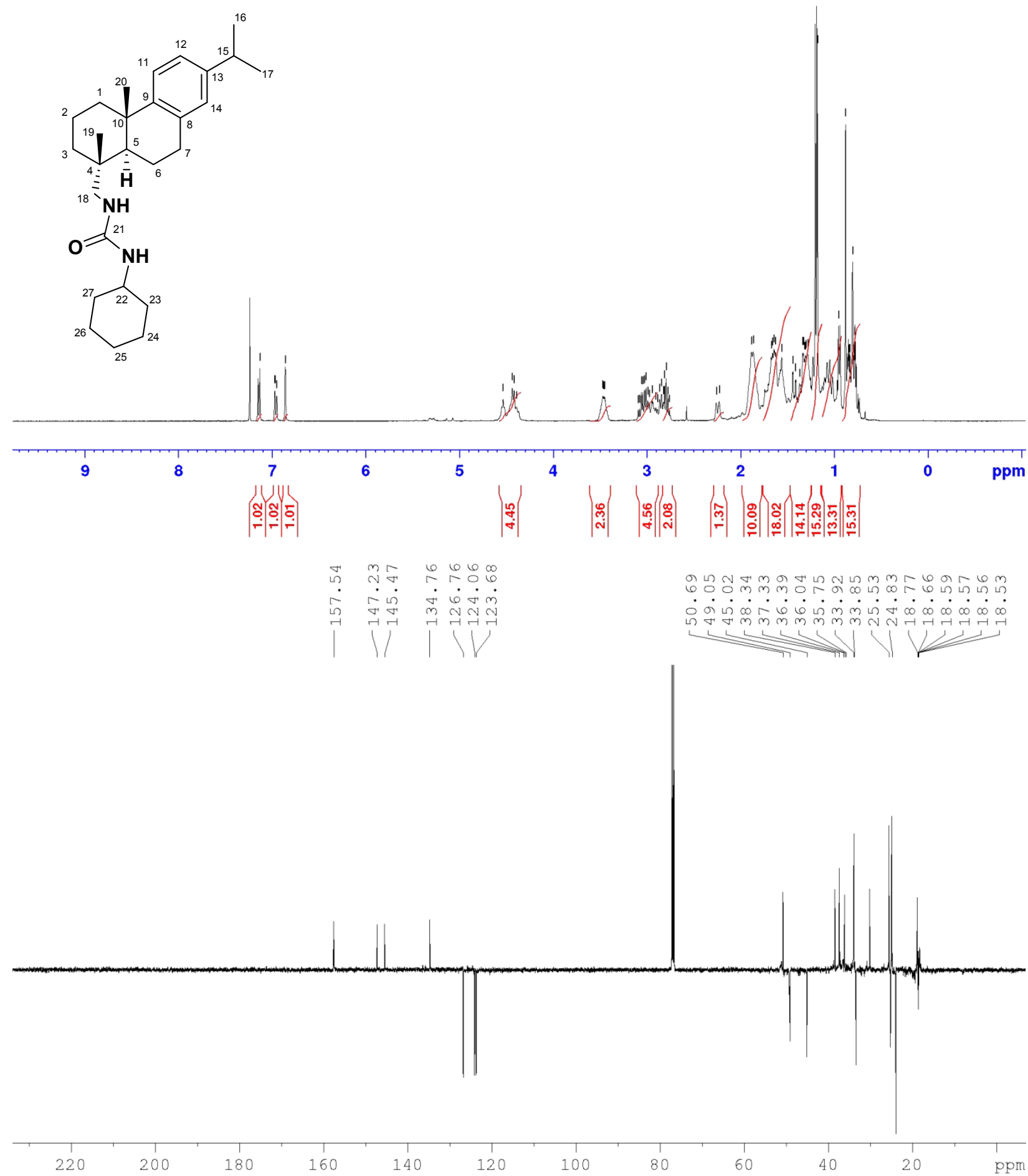


\subsection{Compound 3}
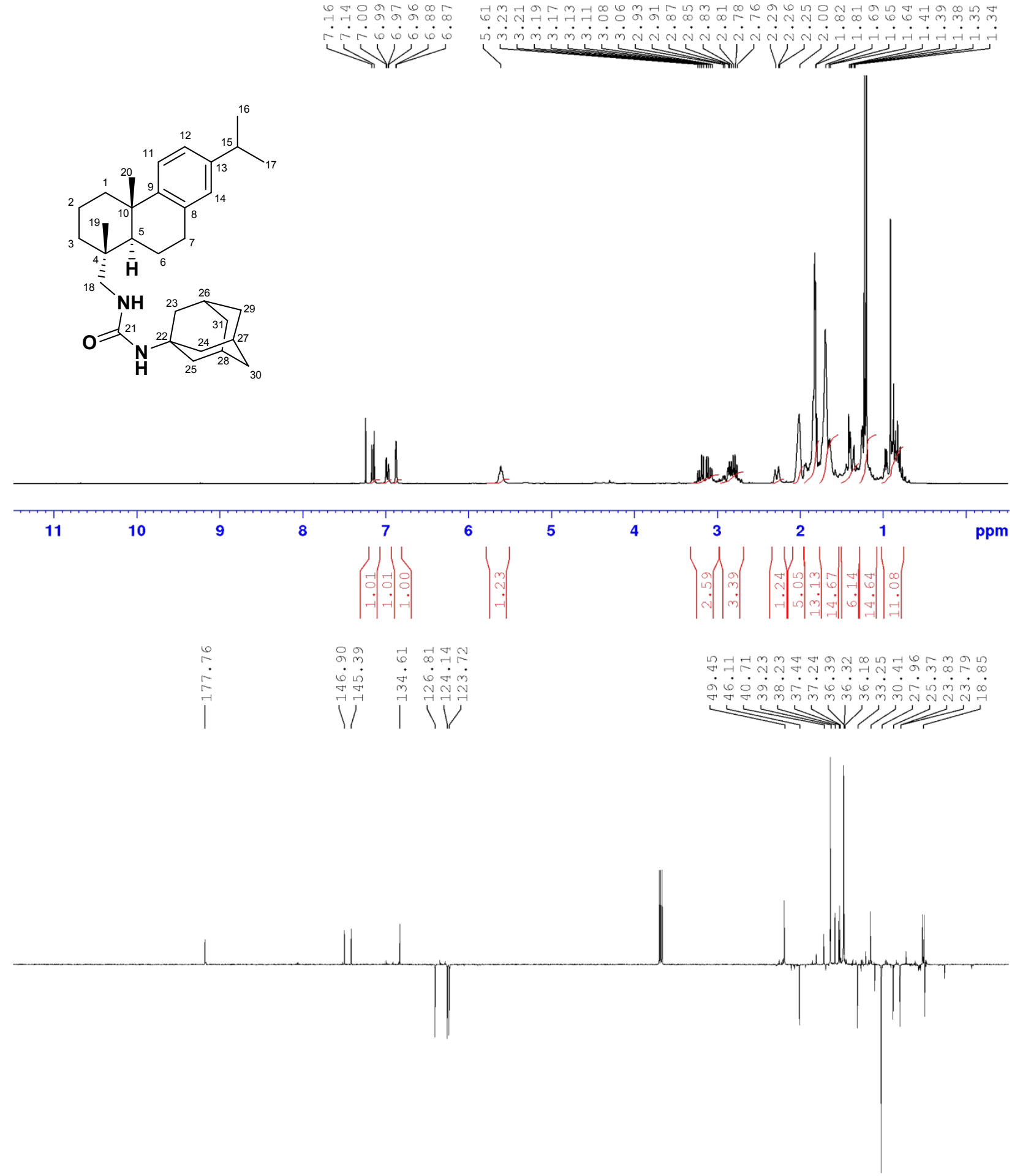

$\begin{array}{lllllllllllllllllllll}210 & 200 & 190 & 180 & 170 & 160 & 150 & 140 & 130 & 120 & 110 & 100 & 90 & 80 & 70 & 60 & 50 & 40 & 30 & 20 & \text { ppm }\end{array}$ 


\subsection{Compound 4}
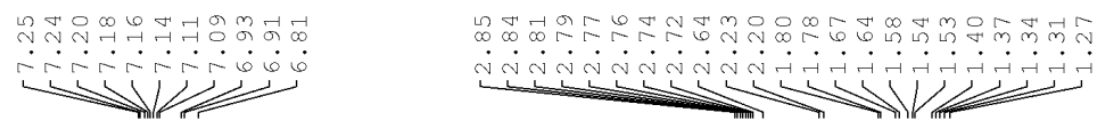

$$
\text { (16) }
$$

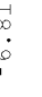
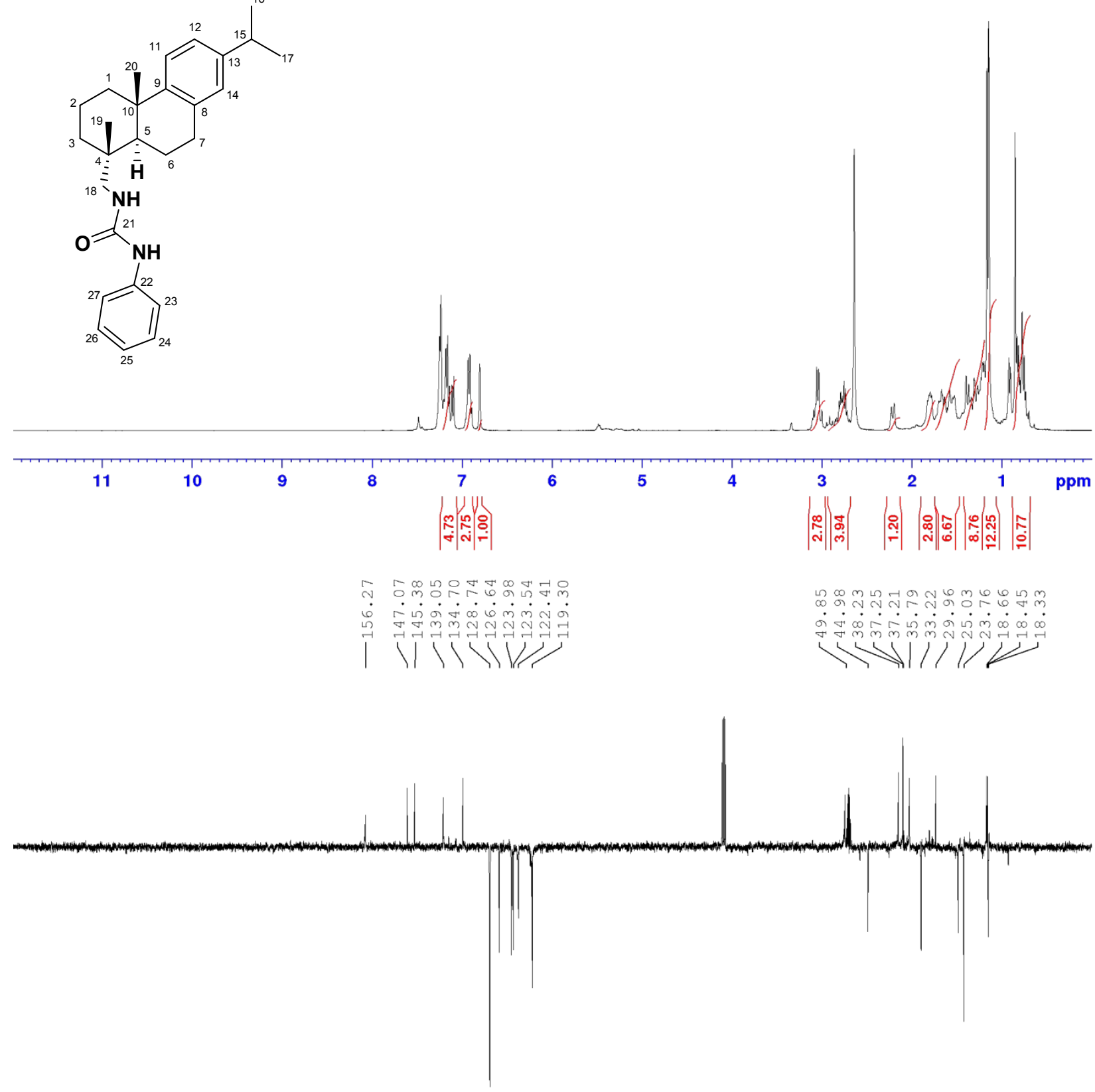


\subsection{Compound 5}

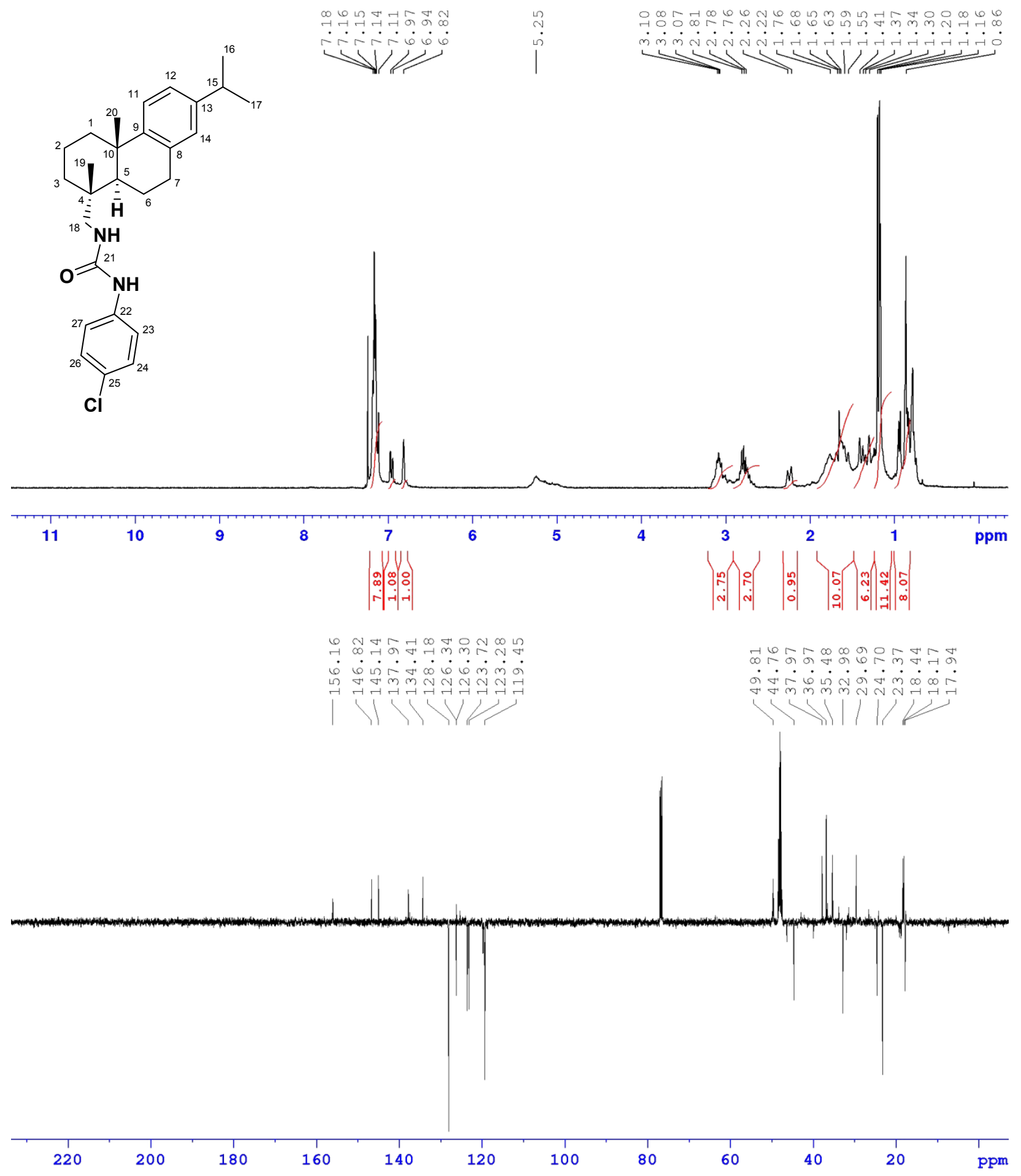




\subsection{Compound 6}

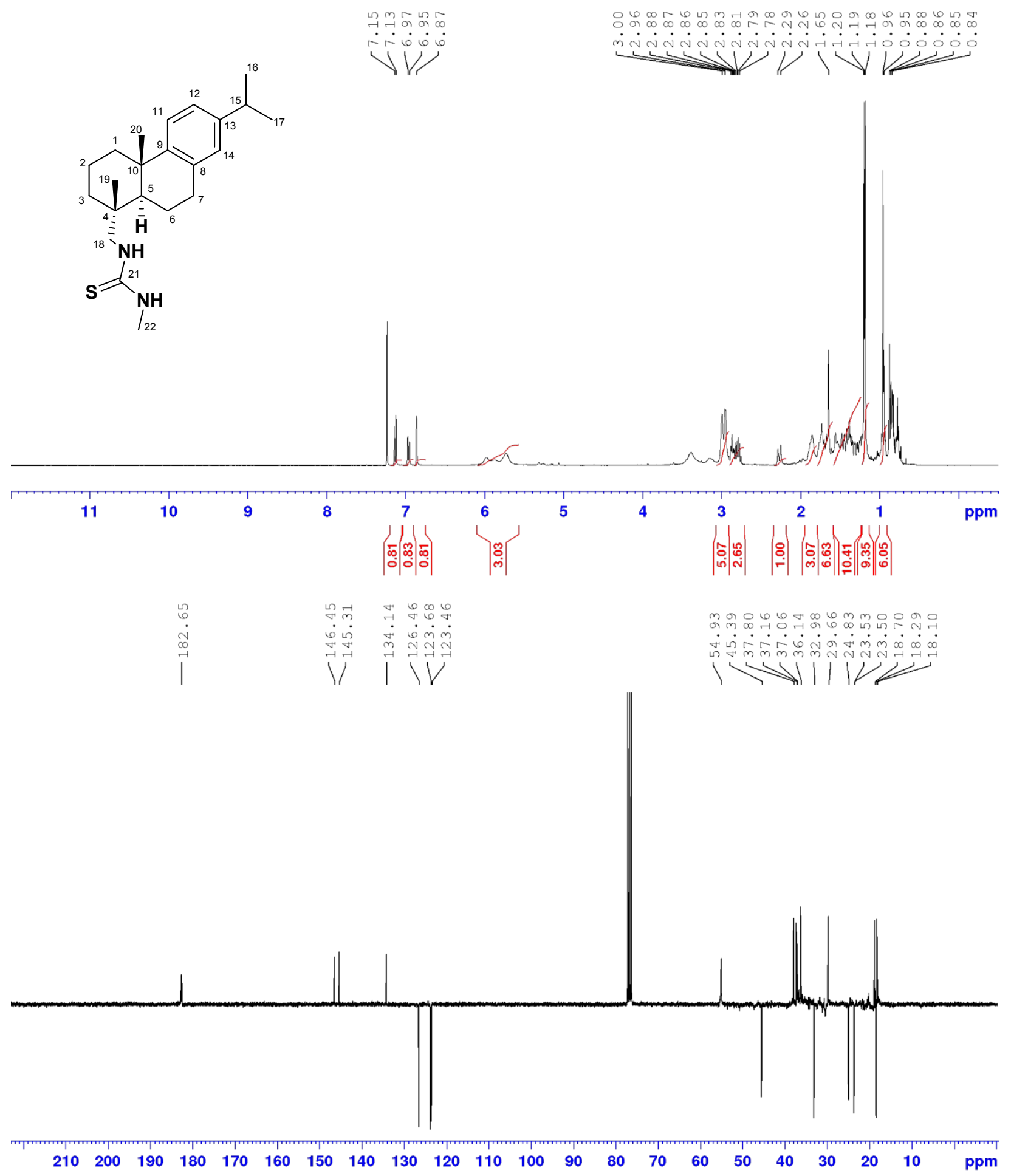




\subsection{Compound 7}

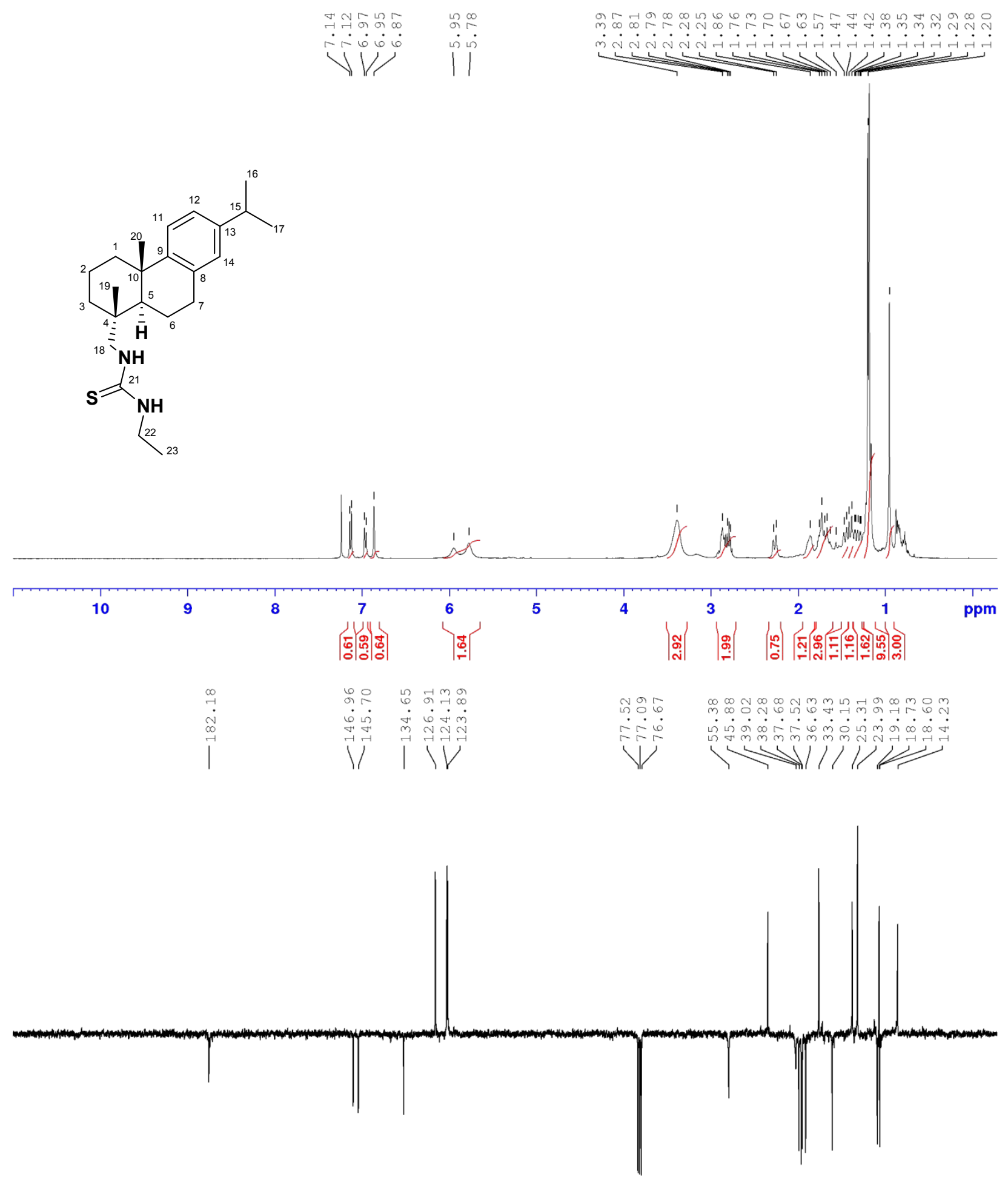

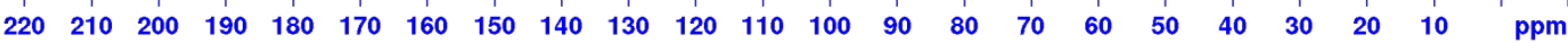




\subsection{Compound 8}

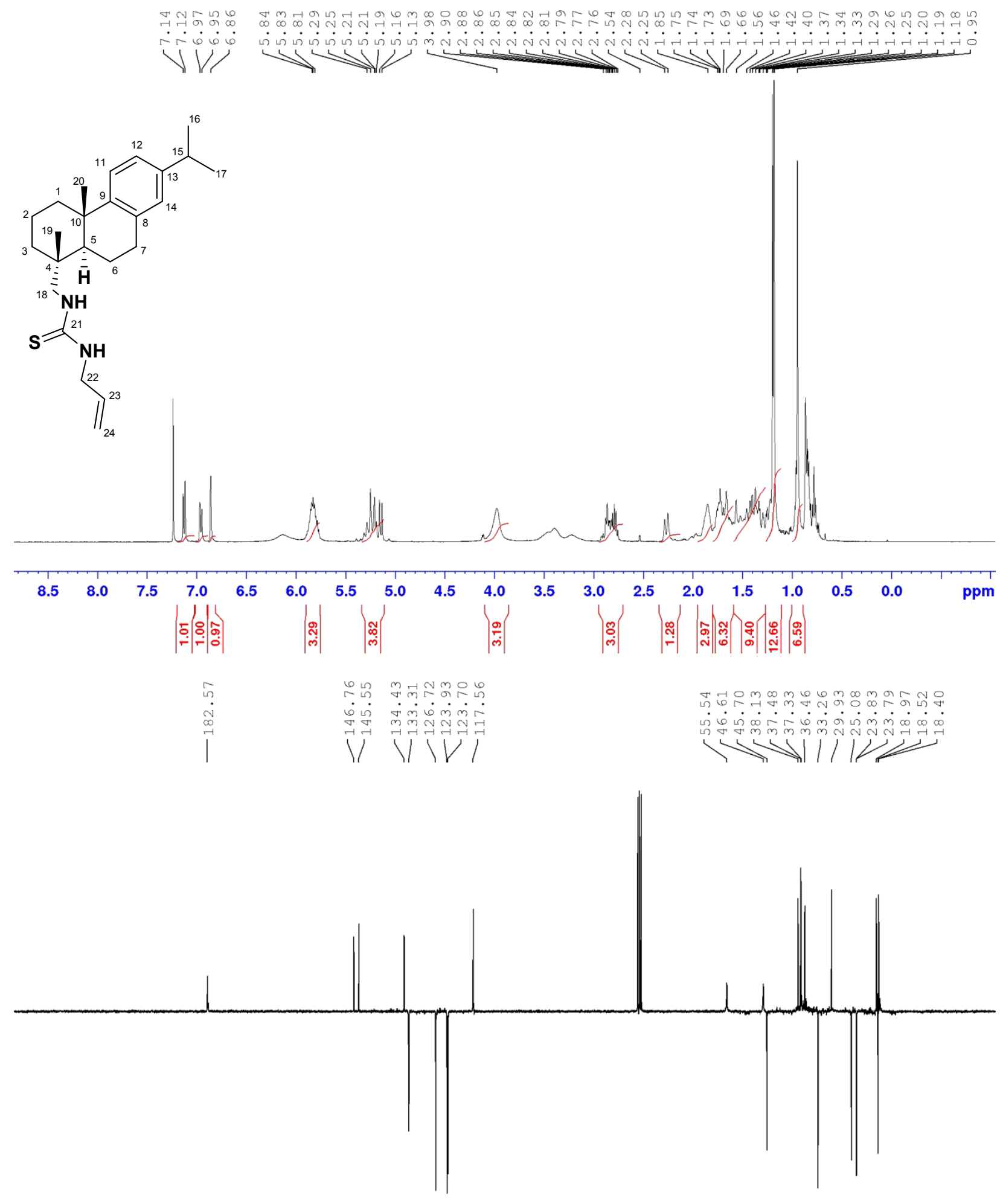

$\begin{array}{llllllllllllllllllllllll}220 & 210 & 200 & 190 & 180 & 170 & 160 & 150 & 140 & 130 & 120 & 110 & 100 & 90 & 80 & 70 & 60 & 50 & 40 & 30 & 20 & 10 & \text { ppm }\end{array}$ 
1.9. Compound 9

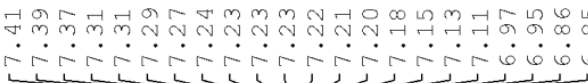

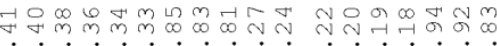

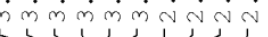
나이<smiles>CC(C)c1ccc2c(c1)CC[C@H]1[C@@H](C)CC[C@H](C)[C@]21CCNC(=S)Nc1ccccc1</smiles>
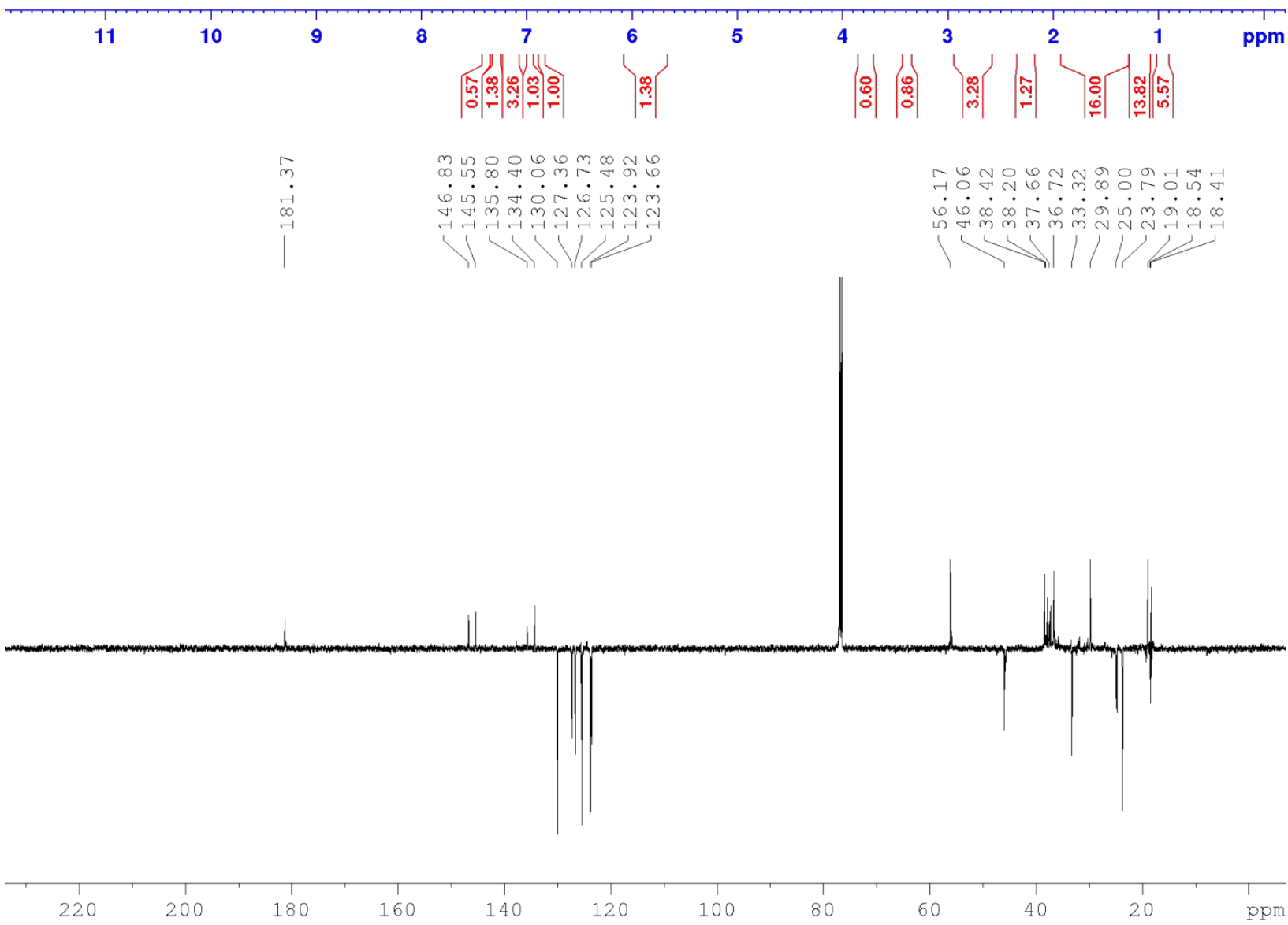
1.10. Compound 10
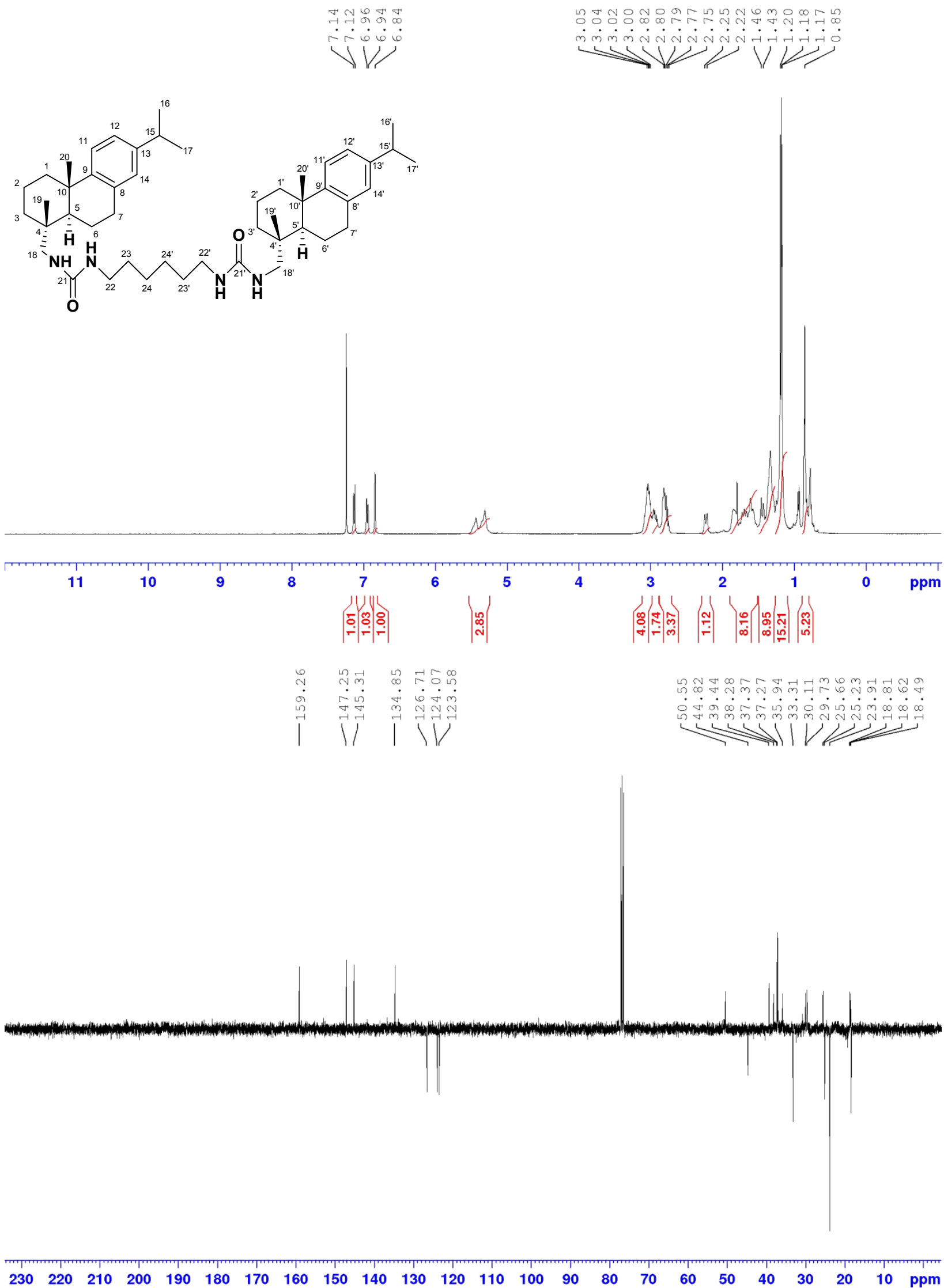
1.11. Compound 11

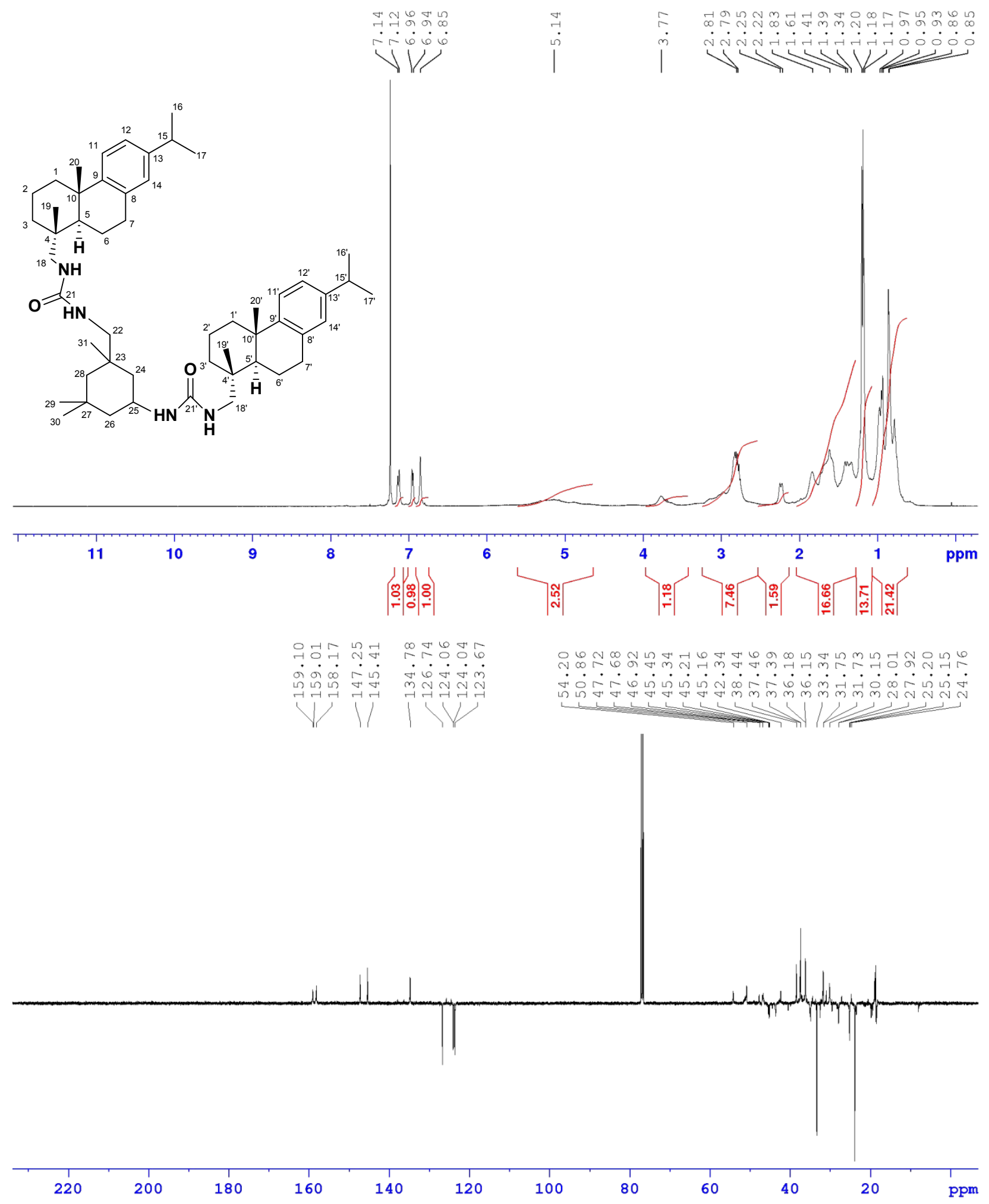


1.12. Compound 12

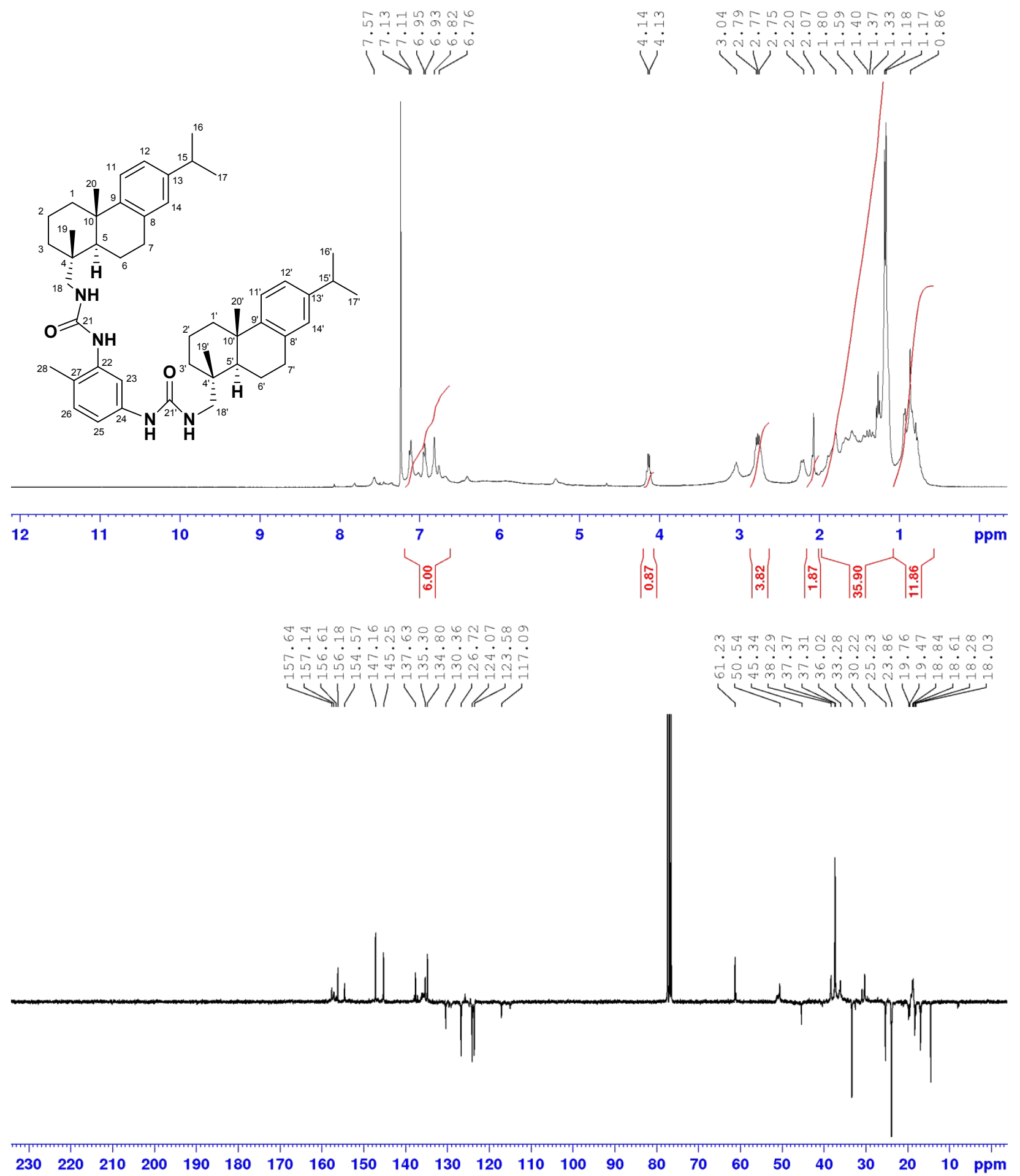




\section{IR spectra of compounds 1-12}

\subsection{Compound 1}

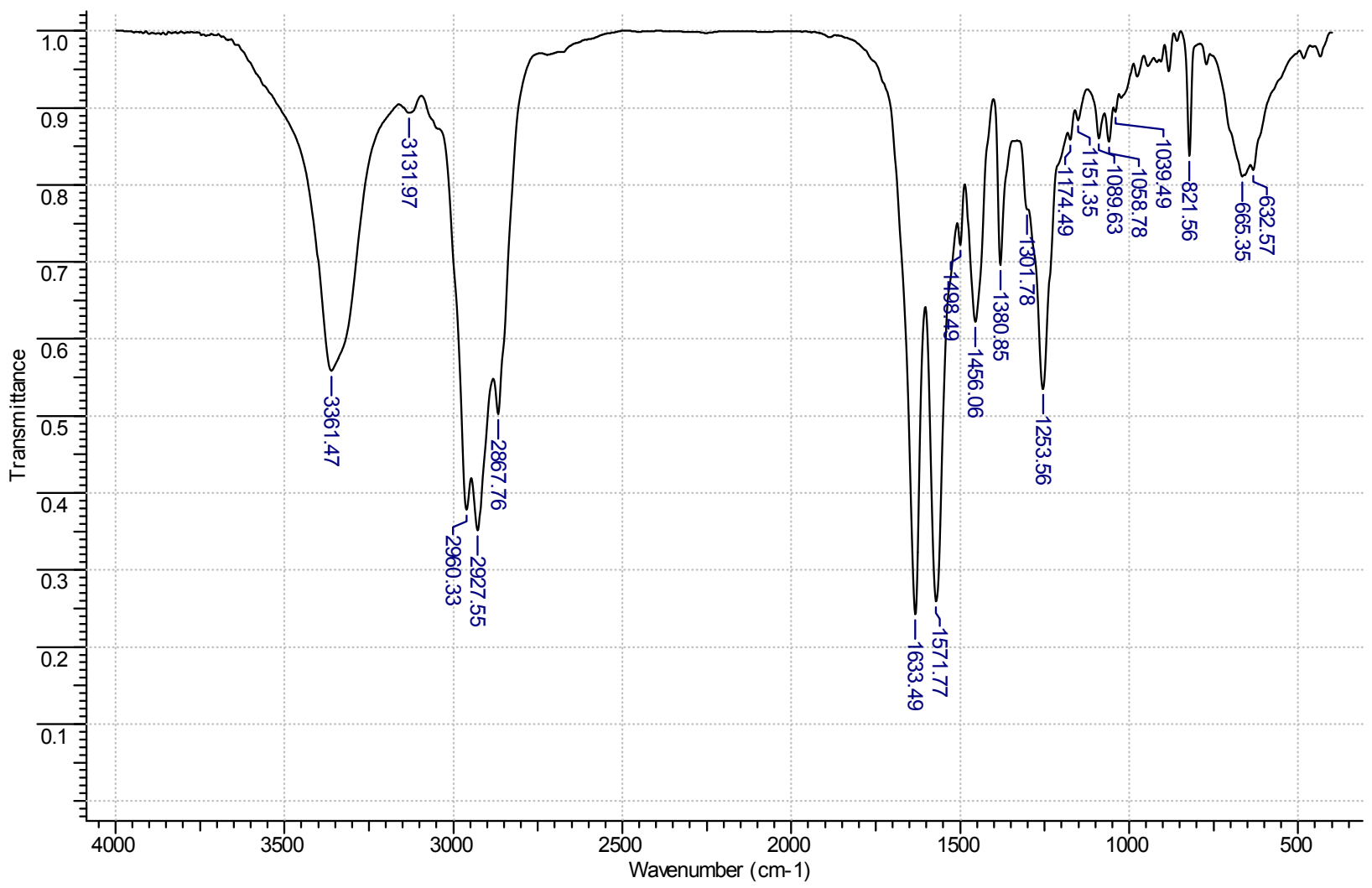

\subsection{Compound 2}

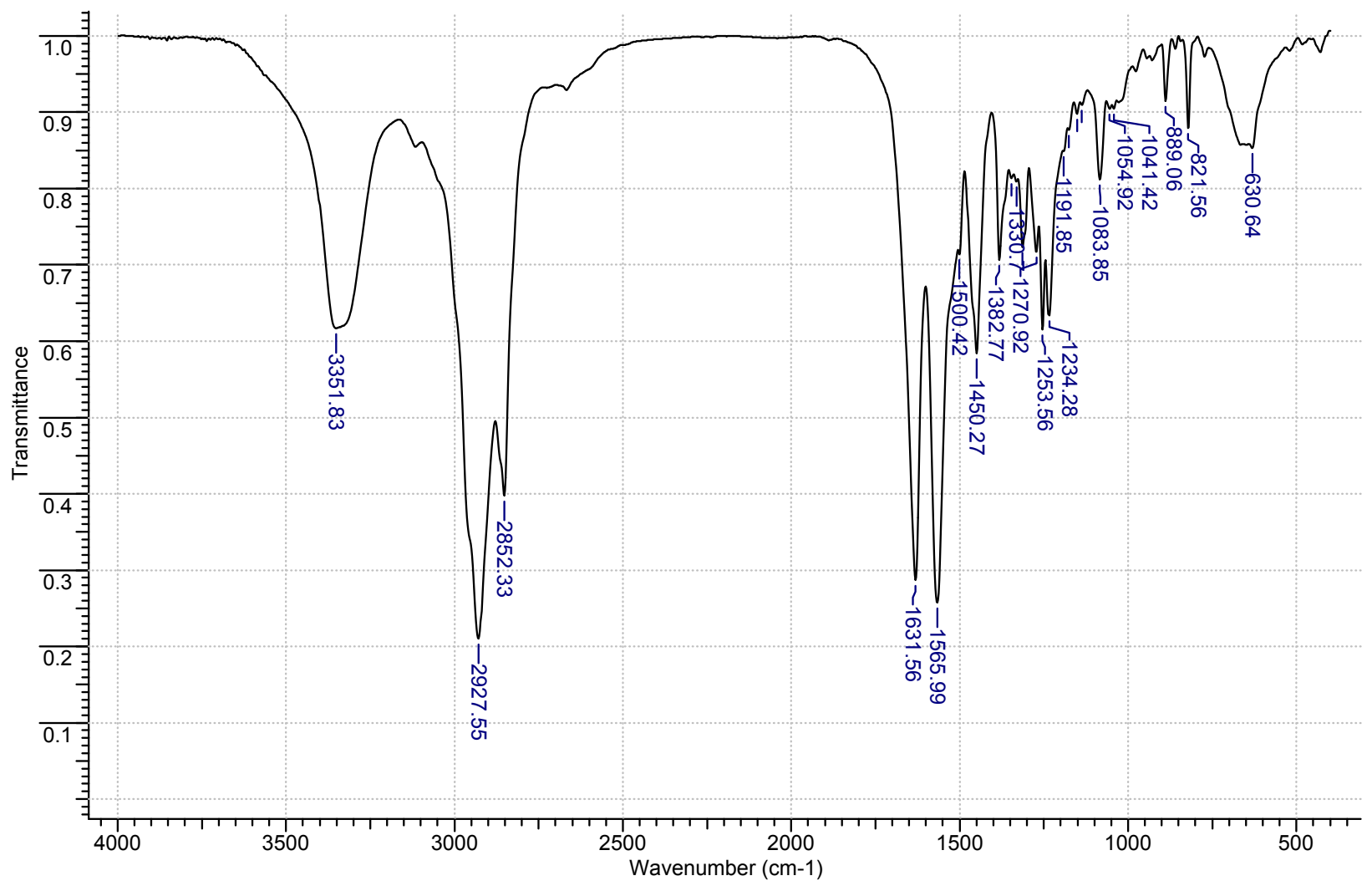


2.3. Compound 3

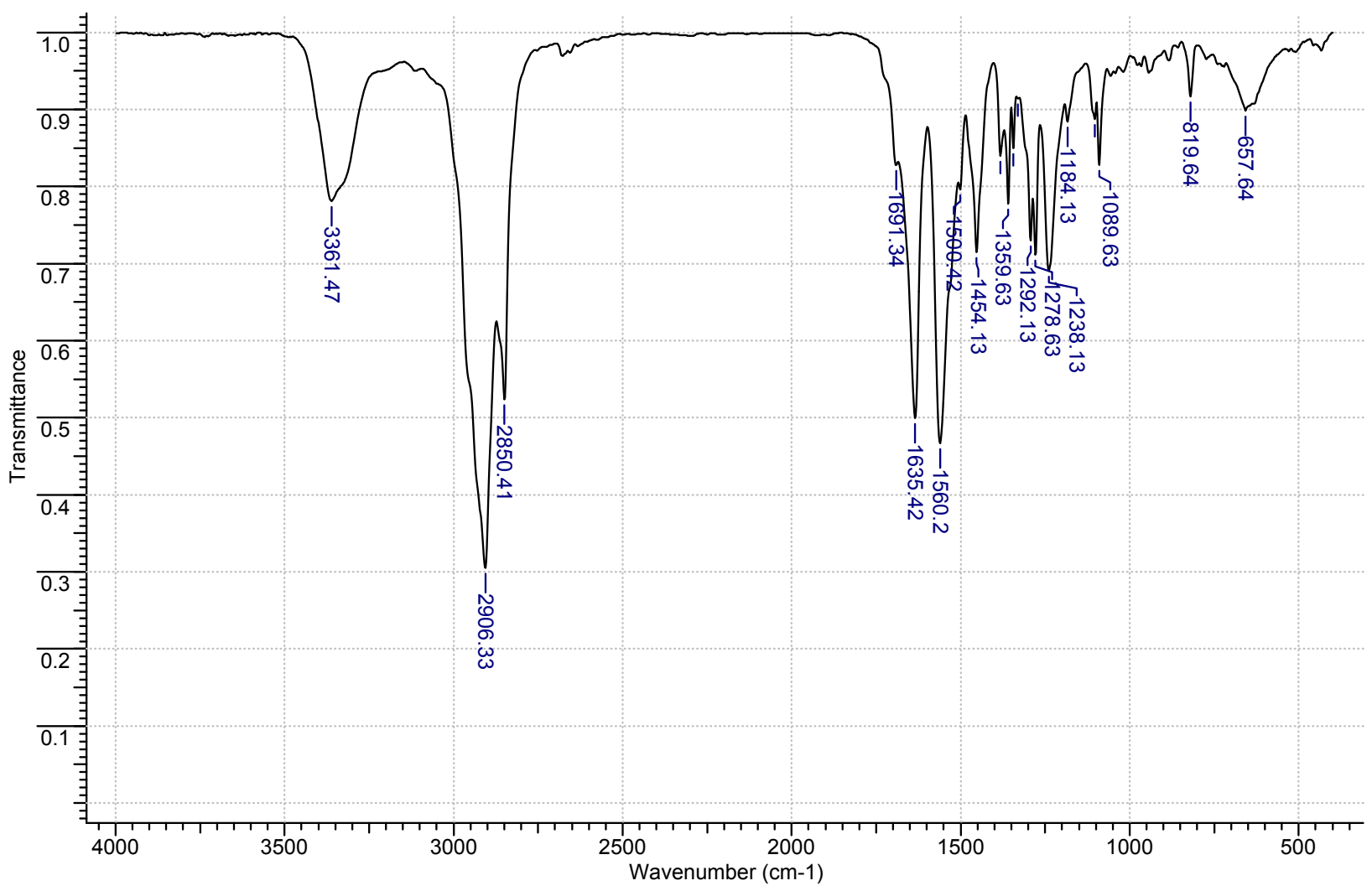

\subsection{Compound 4}

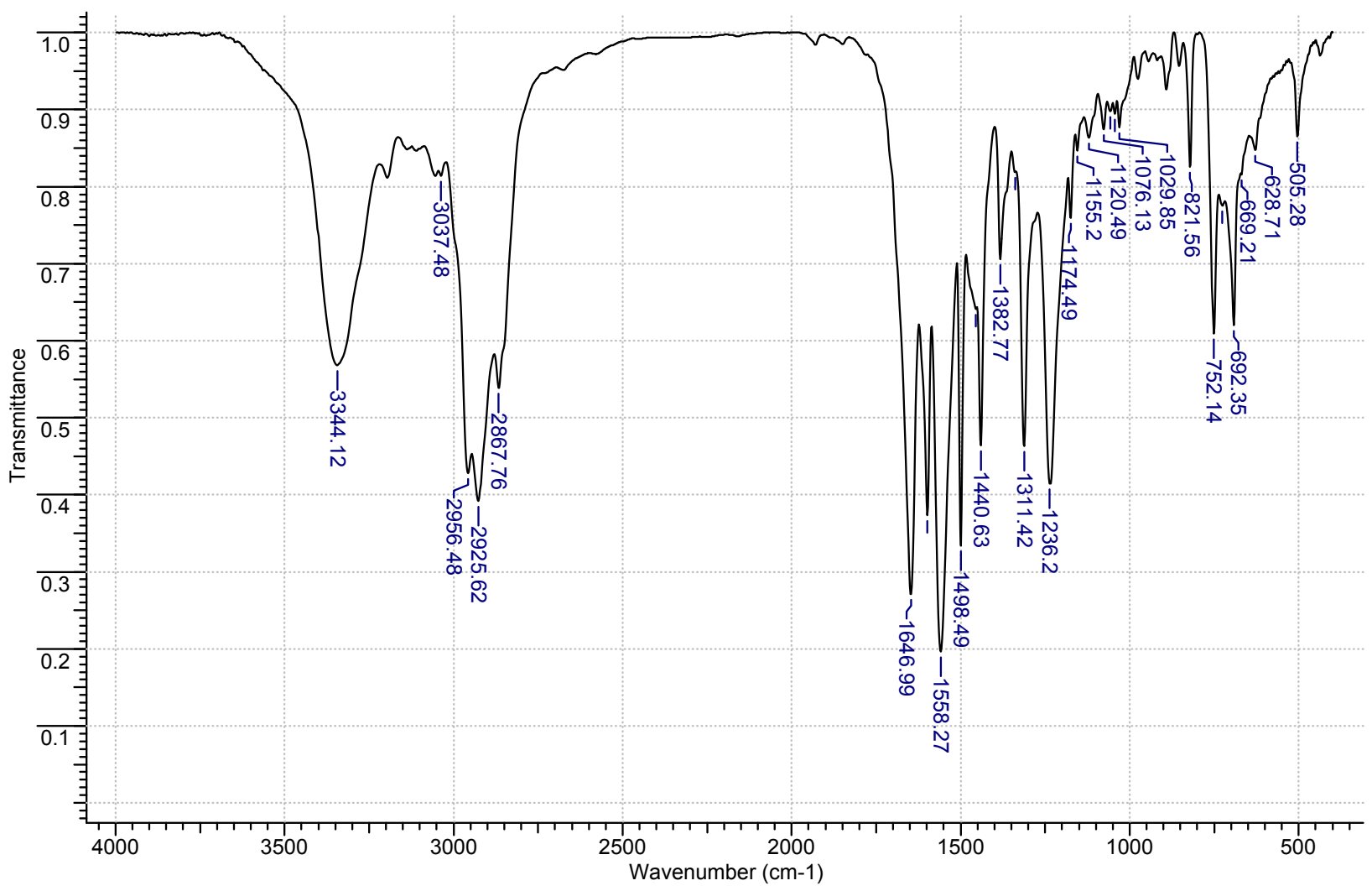




\subsection{Compound 5}

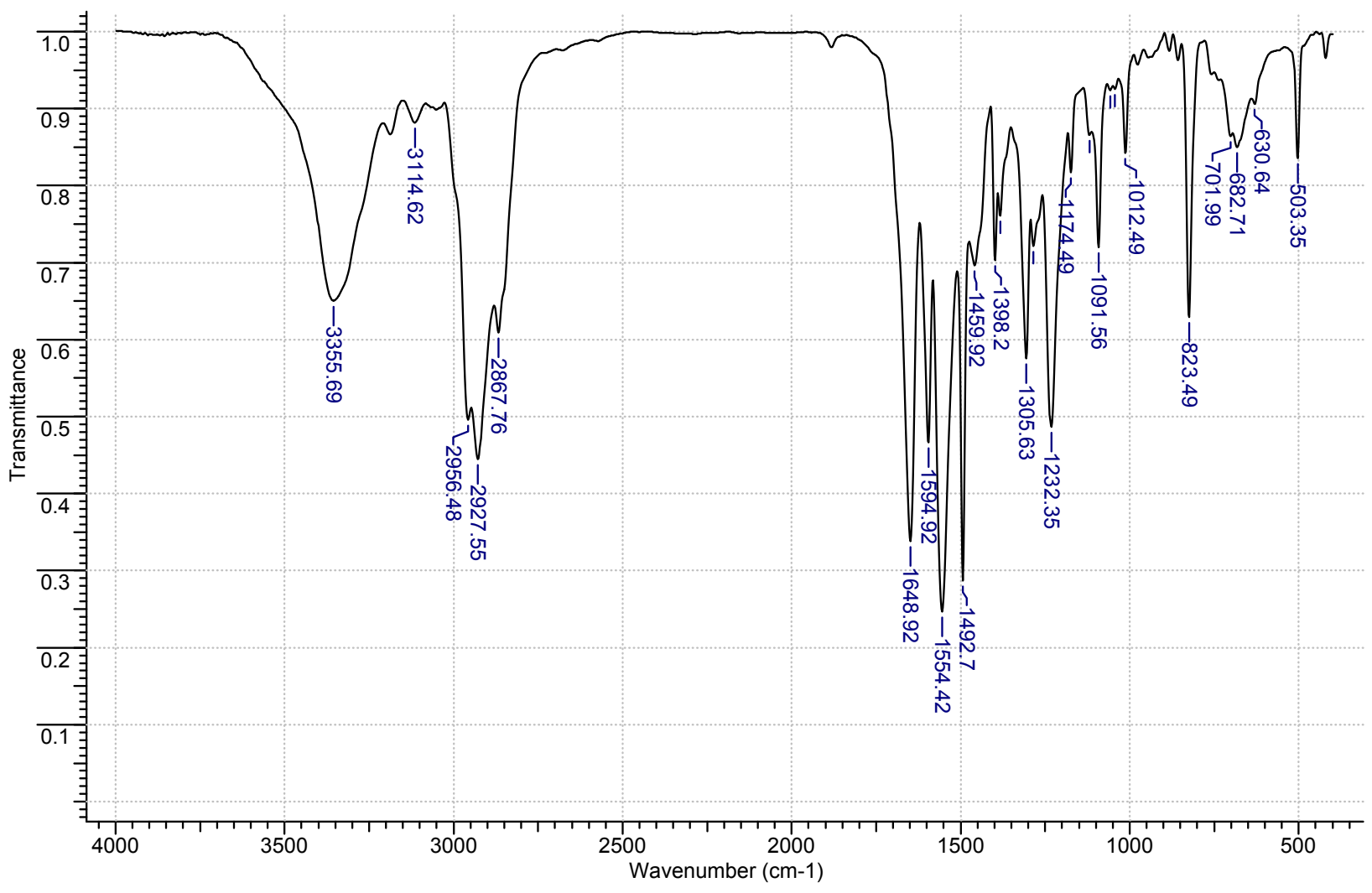

\subsection{Compound 6}

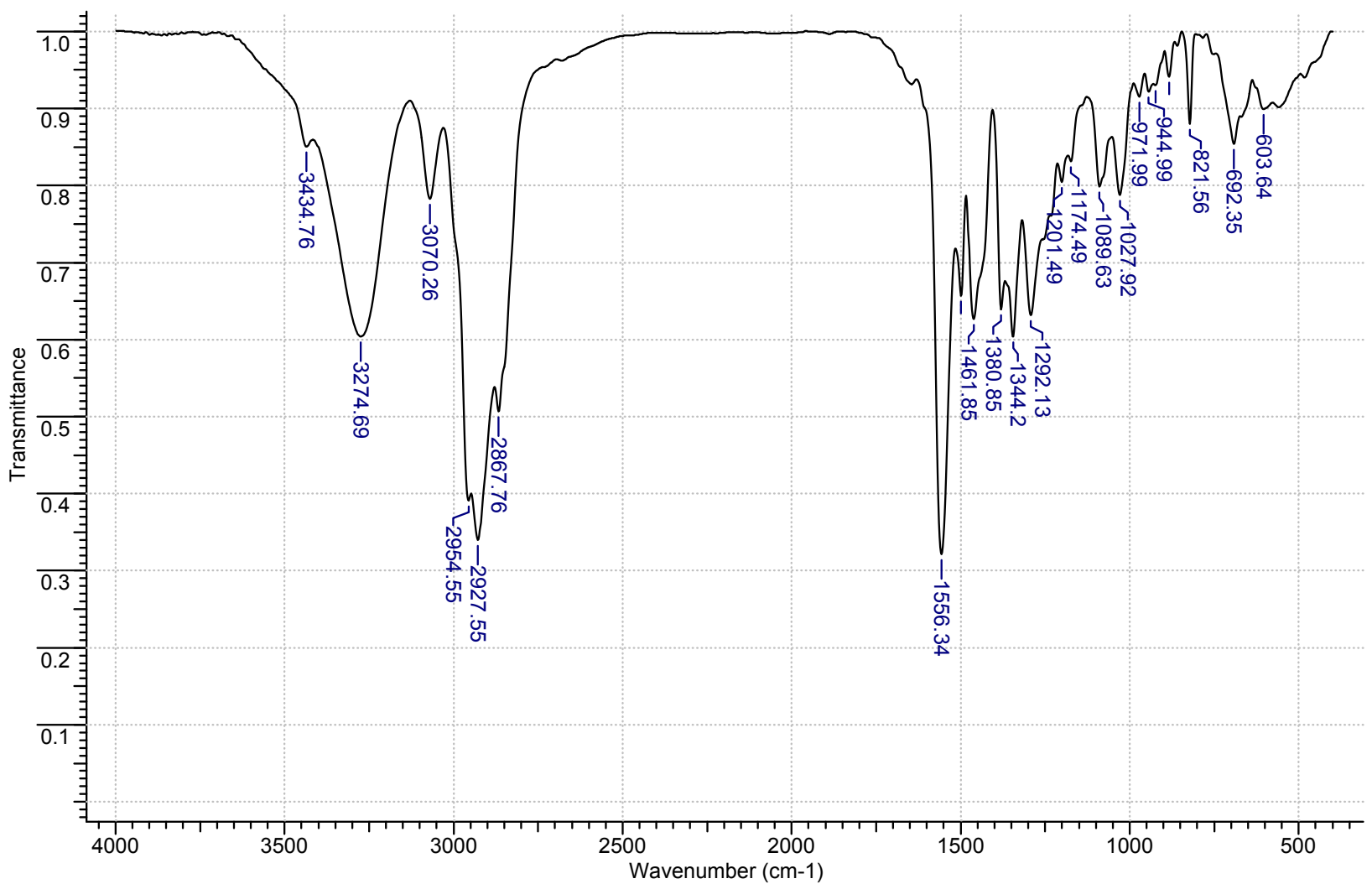




\subsection{Compound 7}

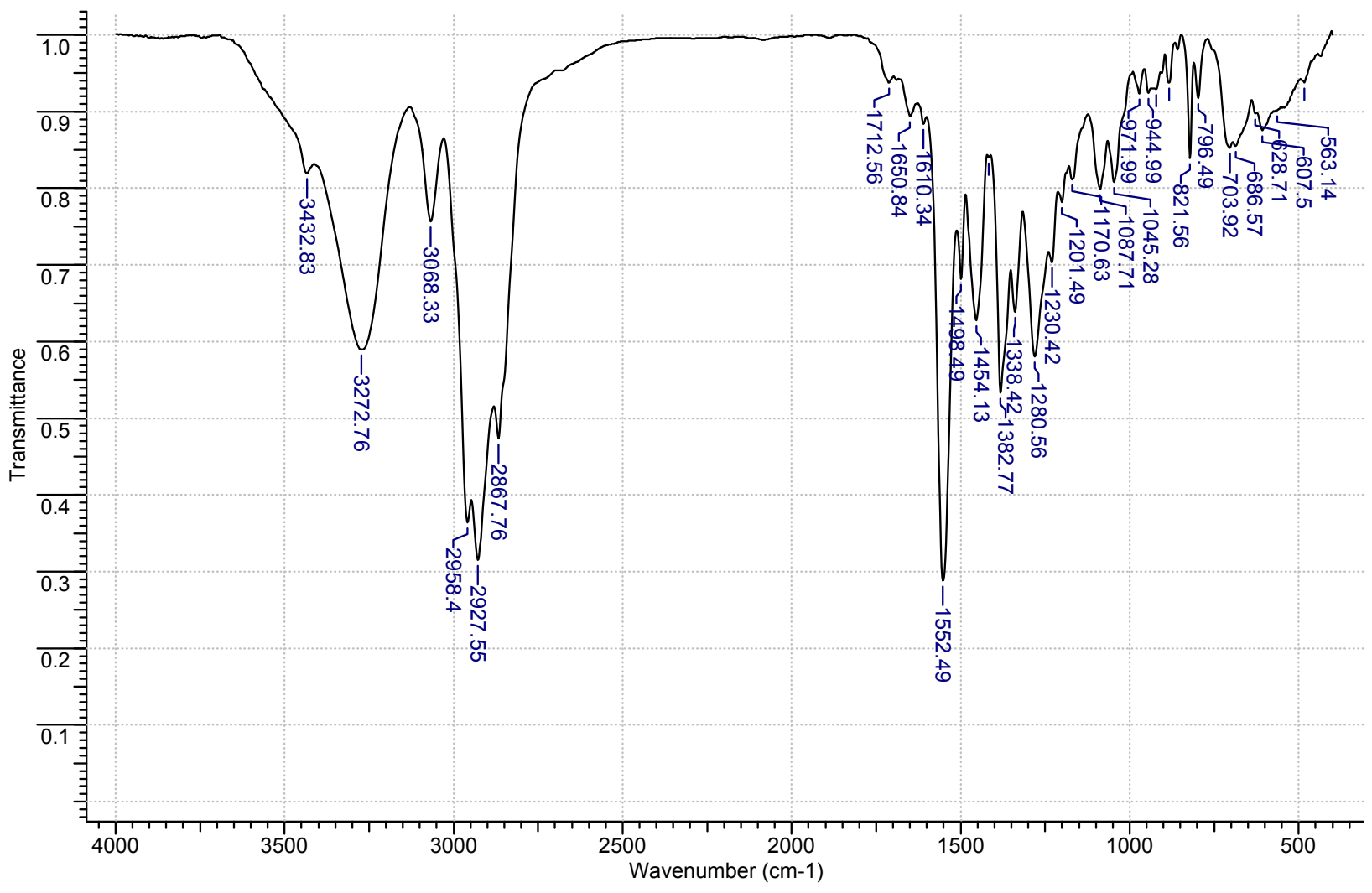

\subsection{Compound 8}

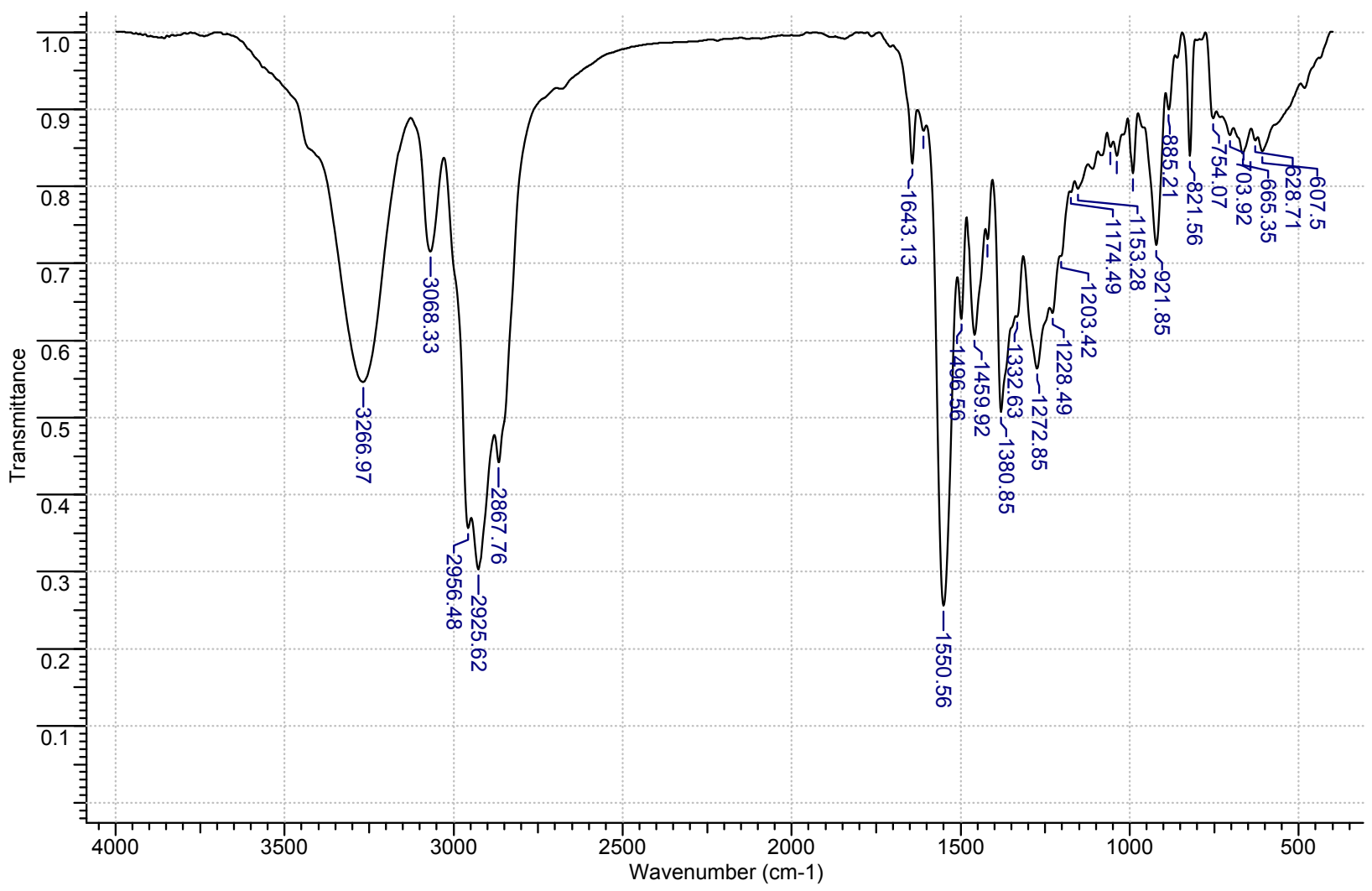


2.9. Compound 9

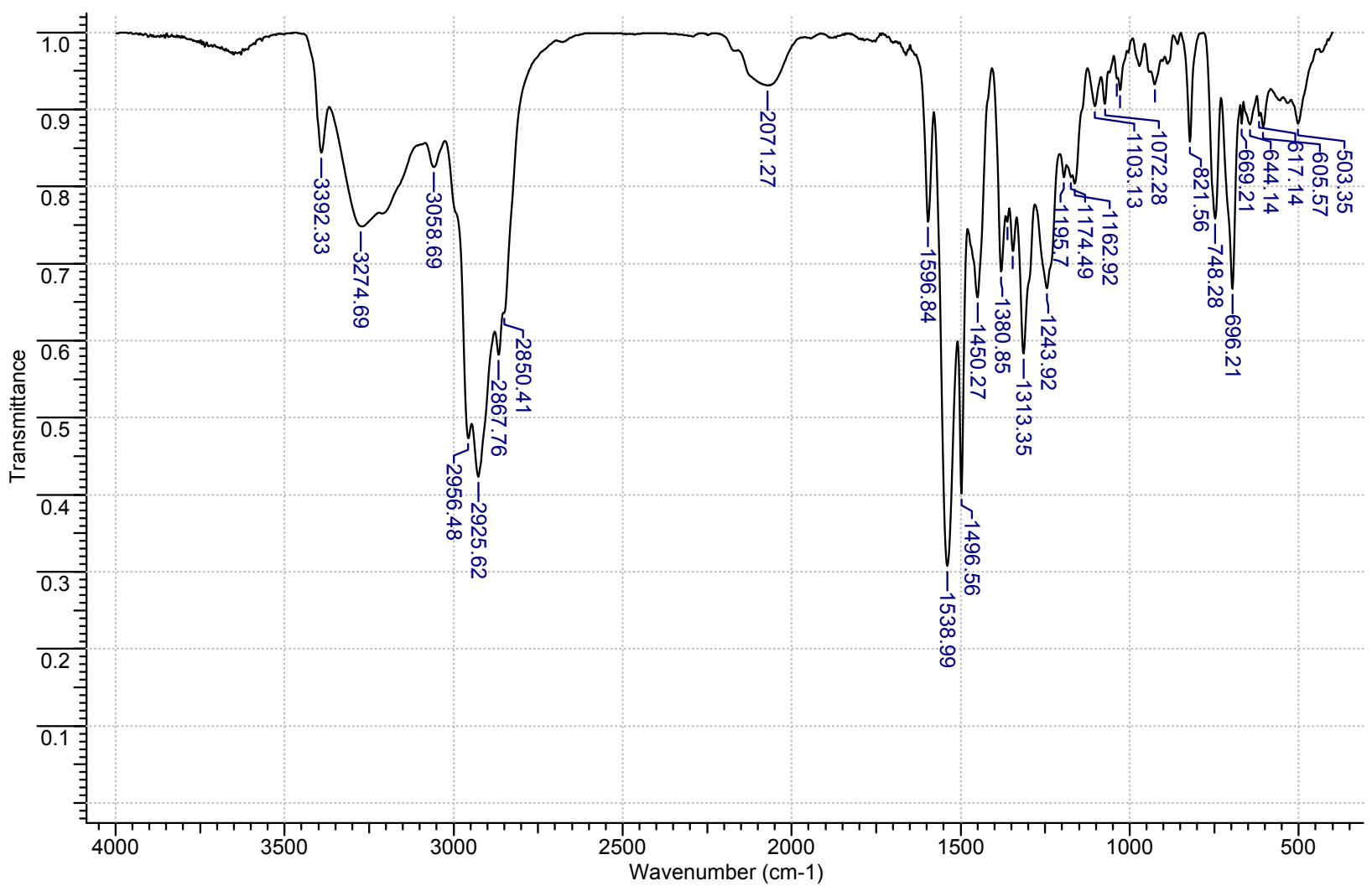

\subsection{Compound 10}

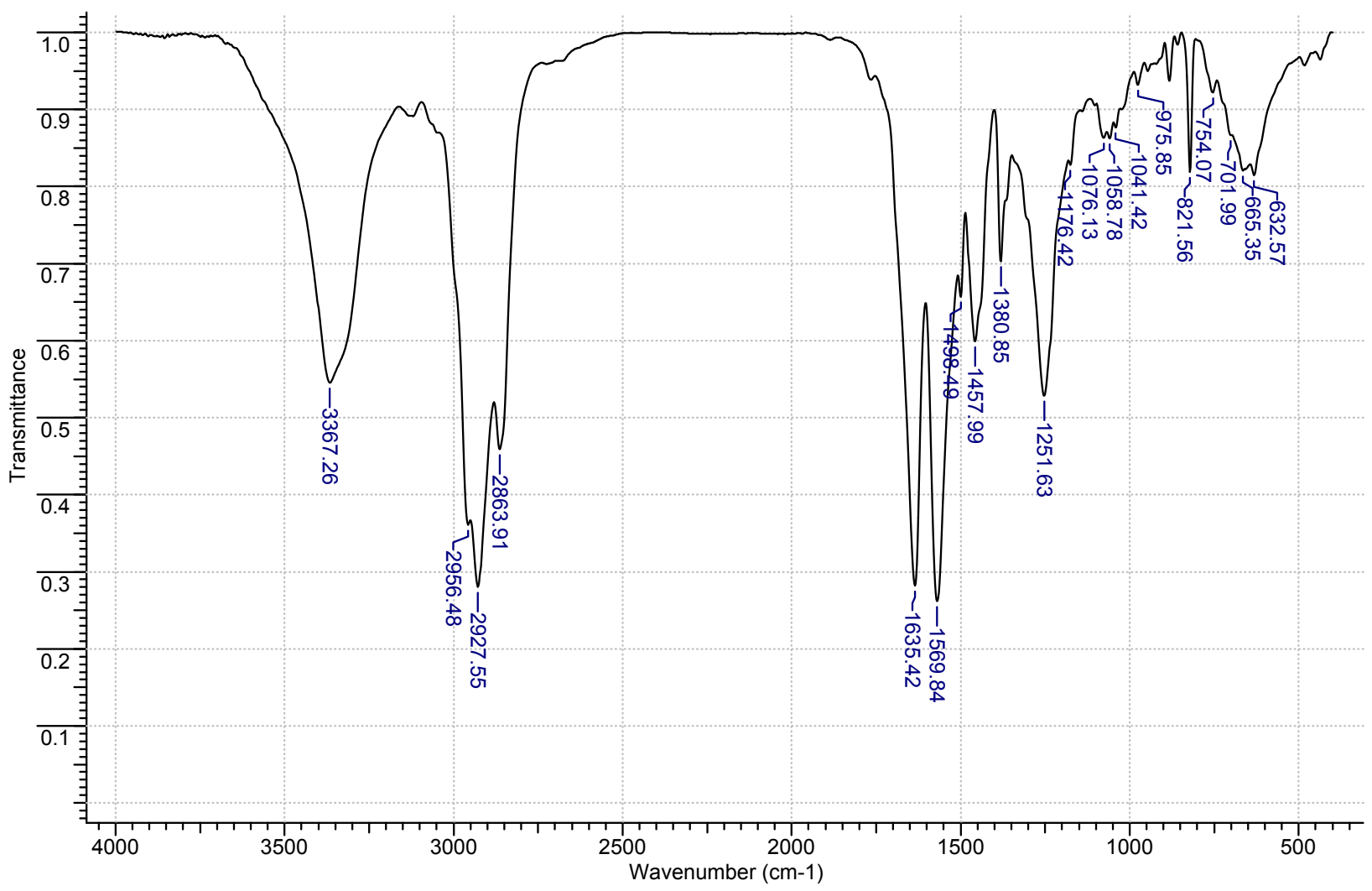


2.11. Compound 11

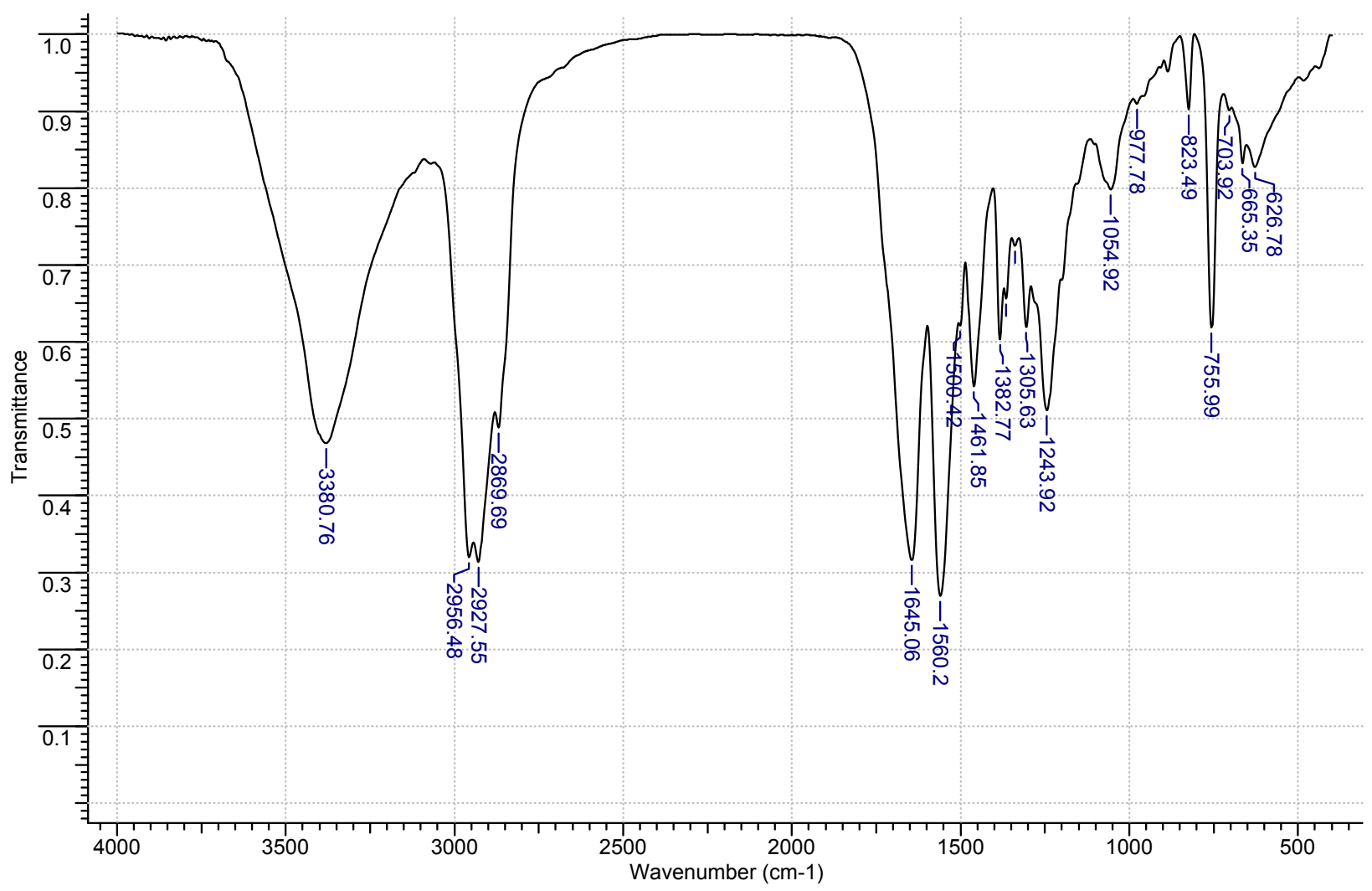

\subsection{Compound 12}

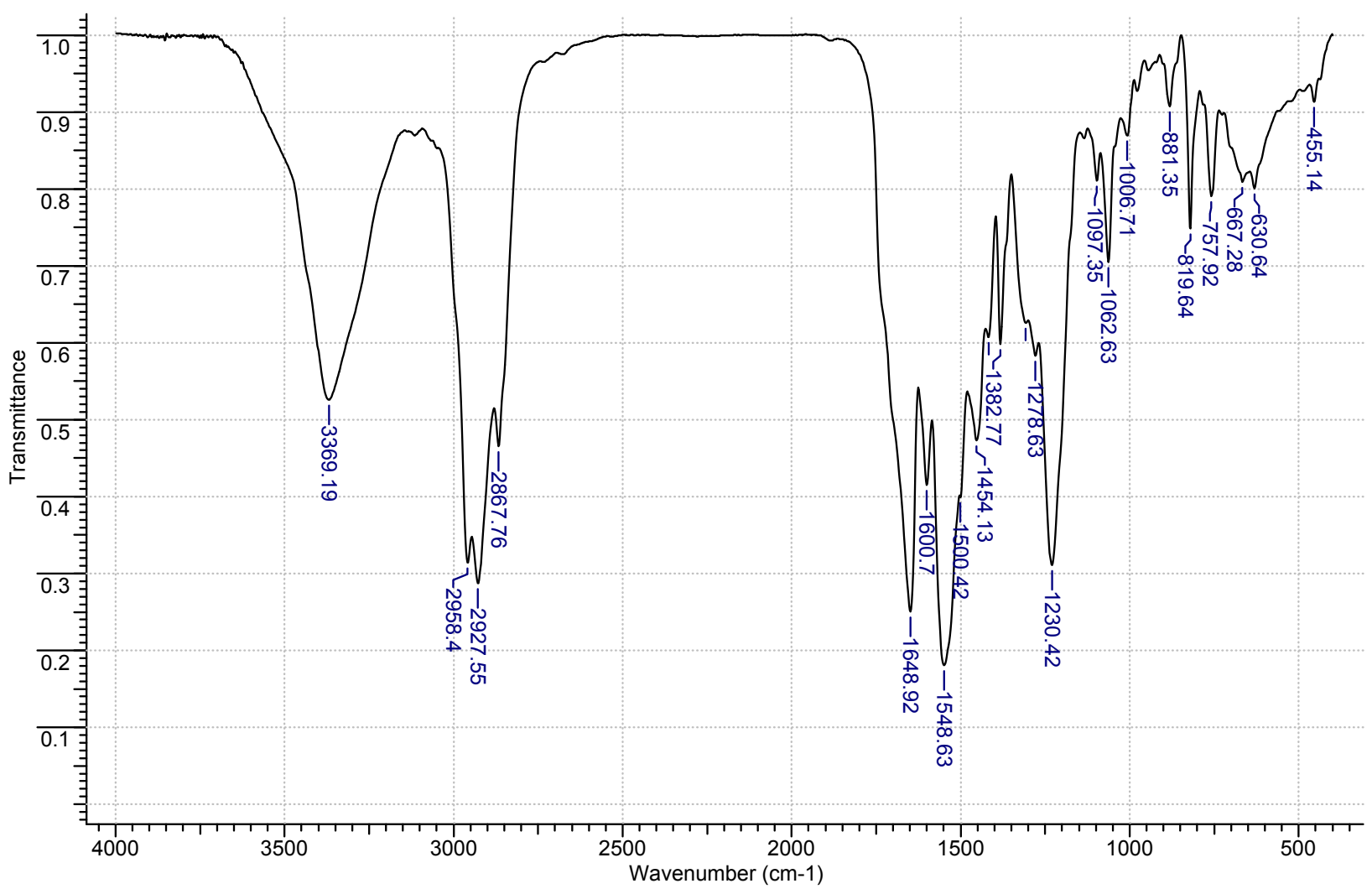




\section{High Resolution Mass Spectra of Compounds 1-12}

\subsection{Compound 1}

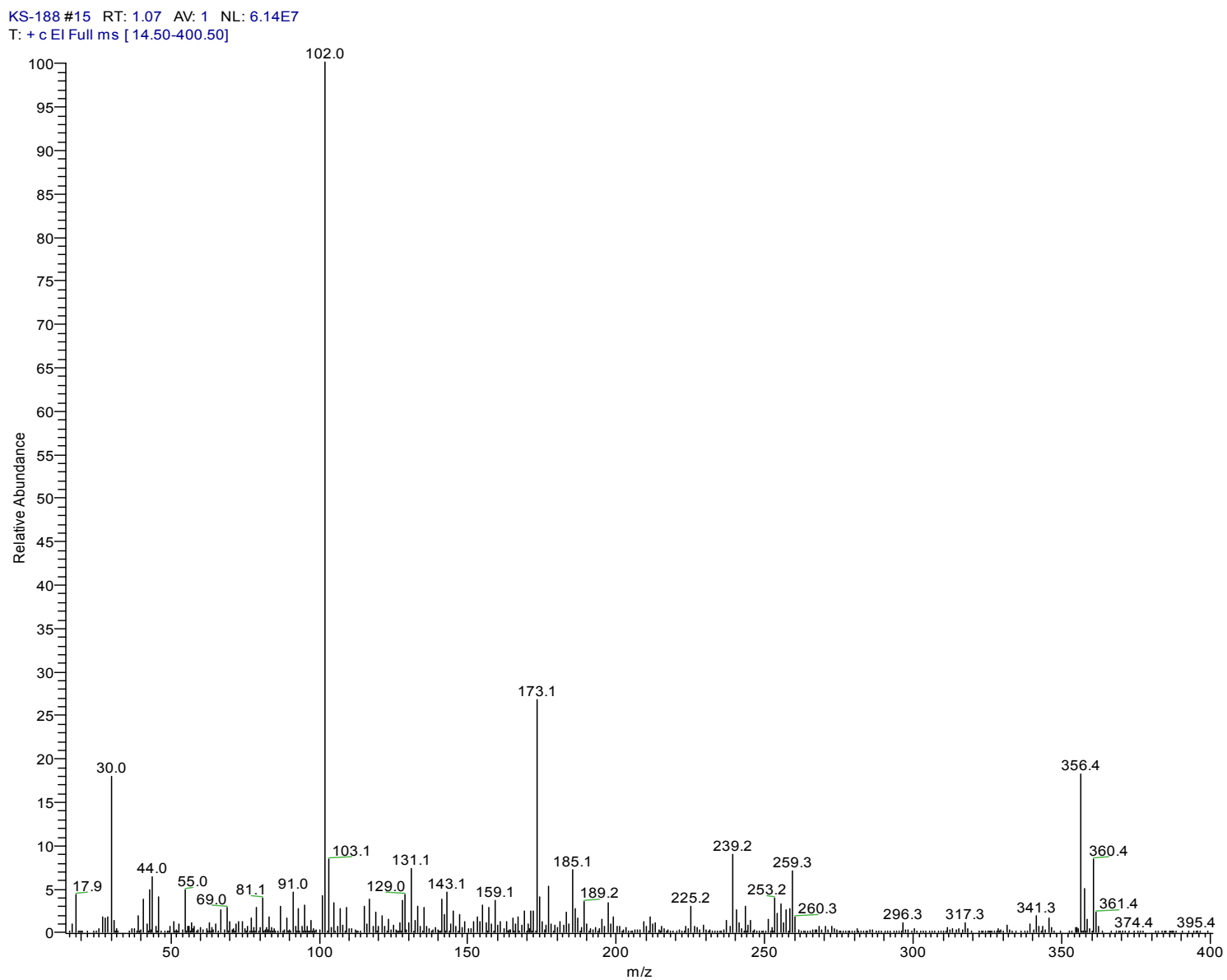

\subsection{Compound 2}

KS-246 \#1 RT: $0.00 \quad$ AV: $1 \quad$ NL: 2.13E7

$\mathrm{T}:+\mathrm{c}$ El Full ms [32.50-450.50]

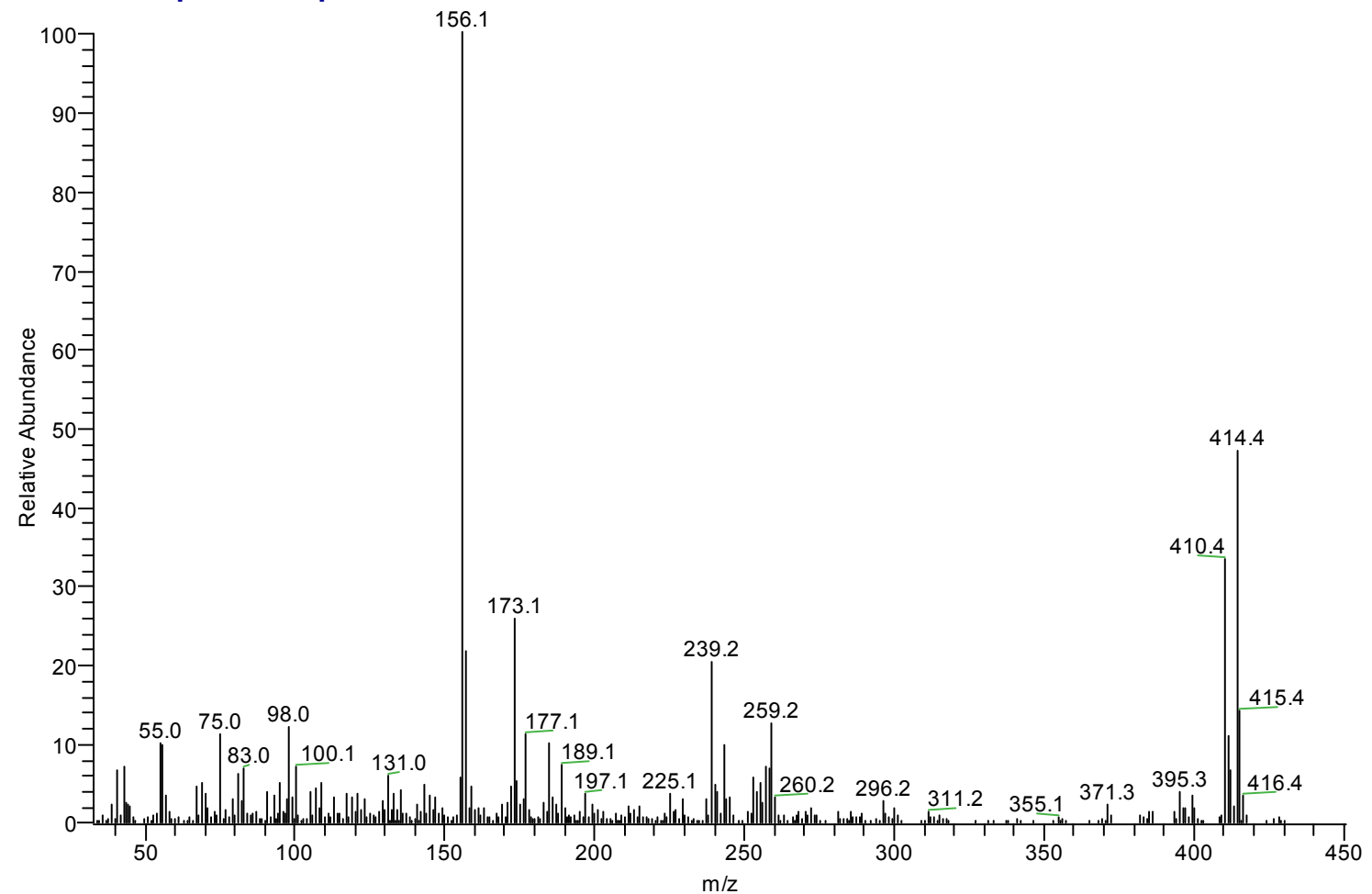




\subsection{Compound 3}

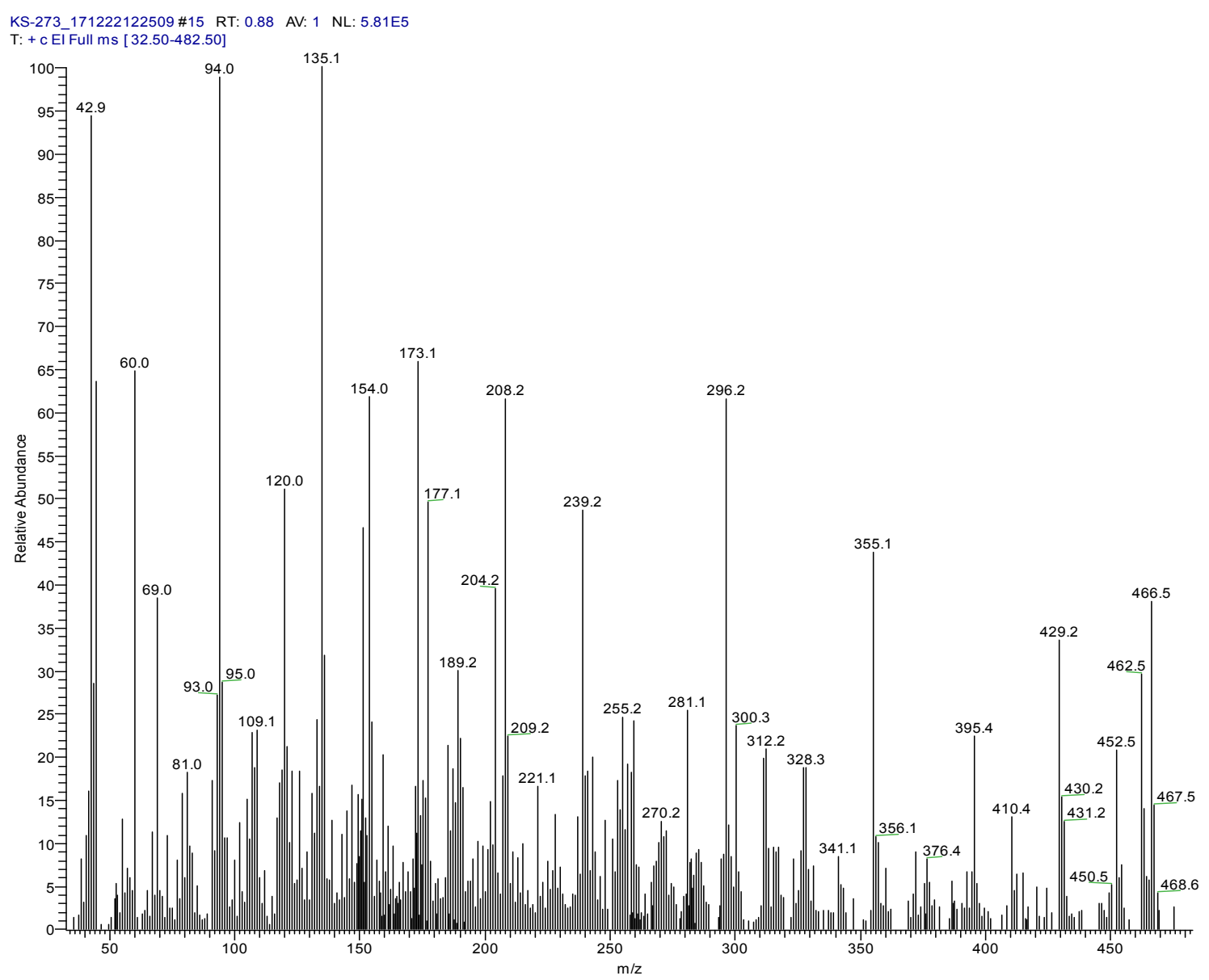

\subsection{Compound 4}

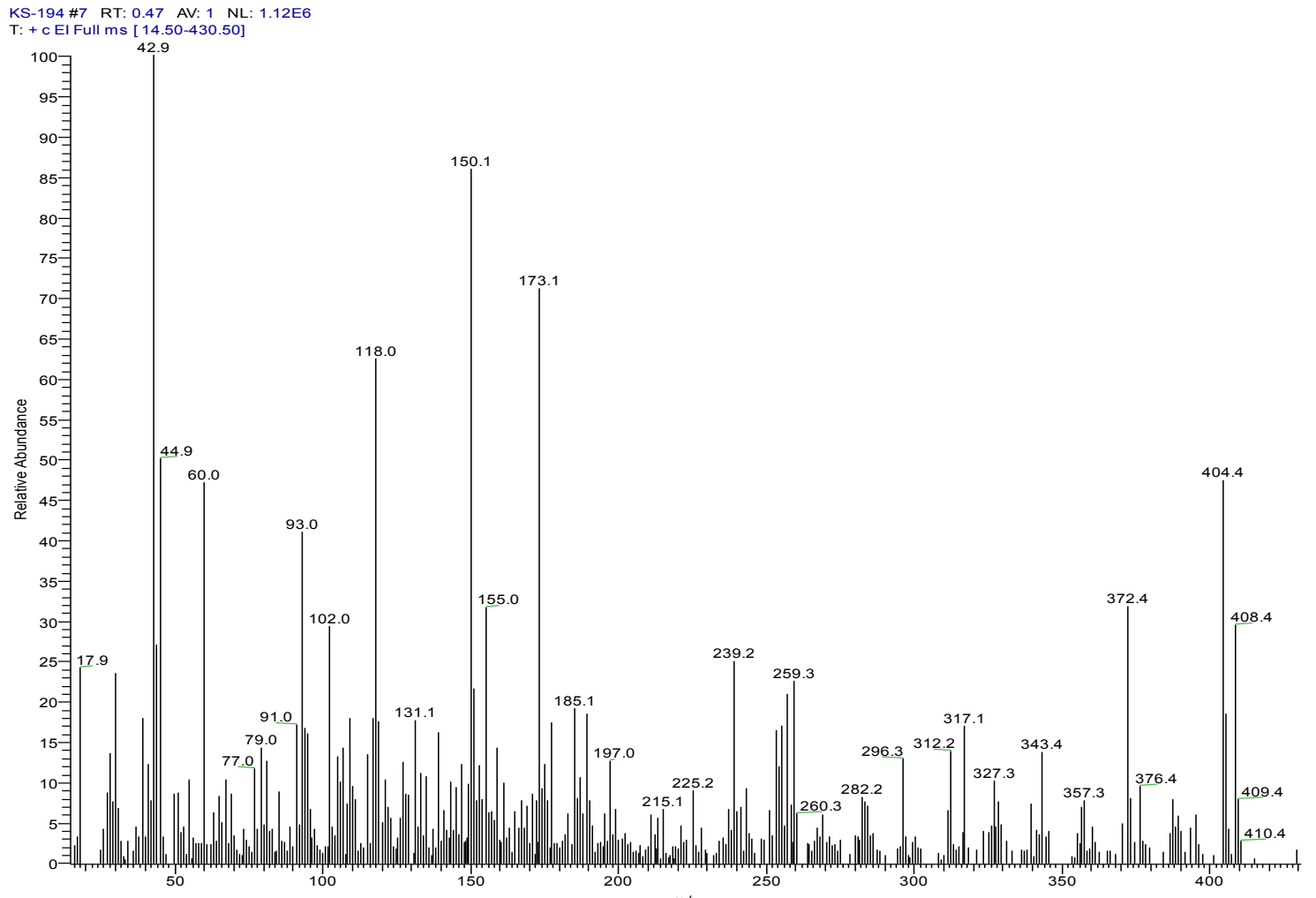




\subsection{Compound 5}

KS-250 \#303 RT: $4.01 \quad$ AV: 1 NL: $1.77 E 7$

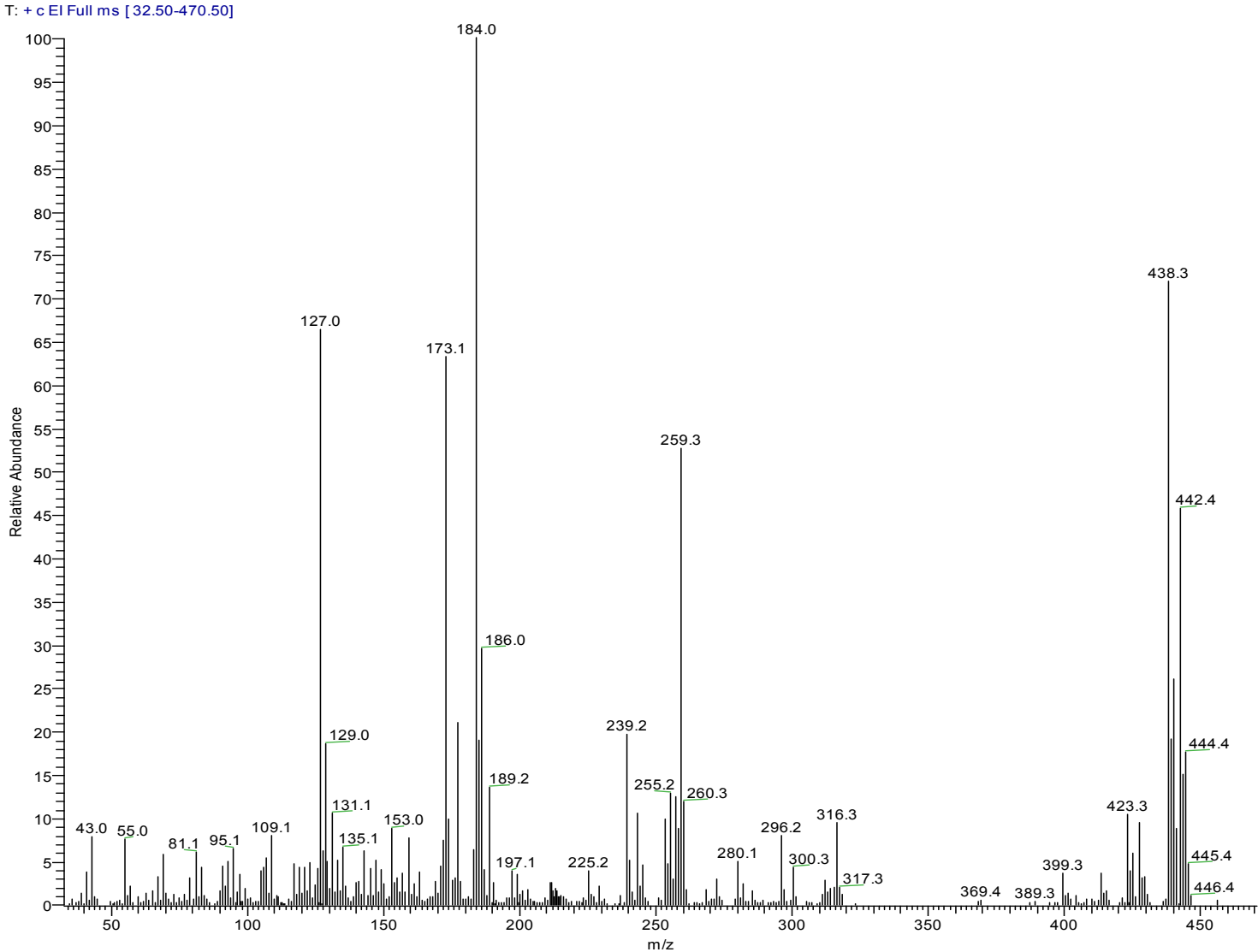

\subsection{Compound 6}

KS-253 \#19 RT: 1.06 AV: 1 NL: $1.31 \mathrm{E} 8$

$\mathrm{T}:+\mathrm{c}$ El Full ms [32.50-400.50]

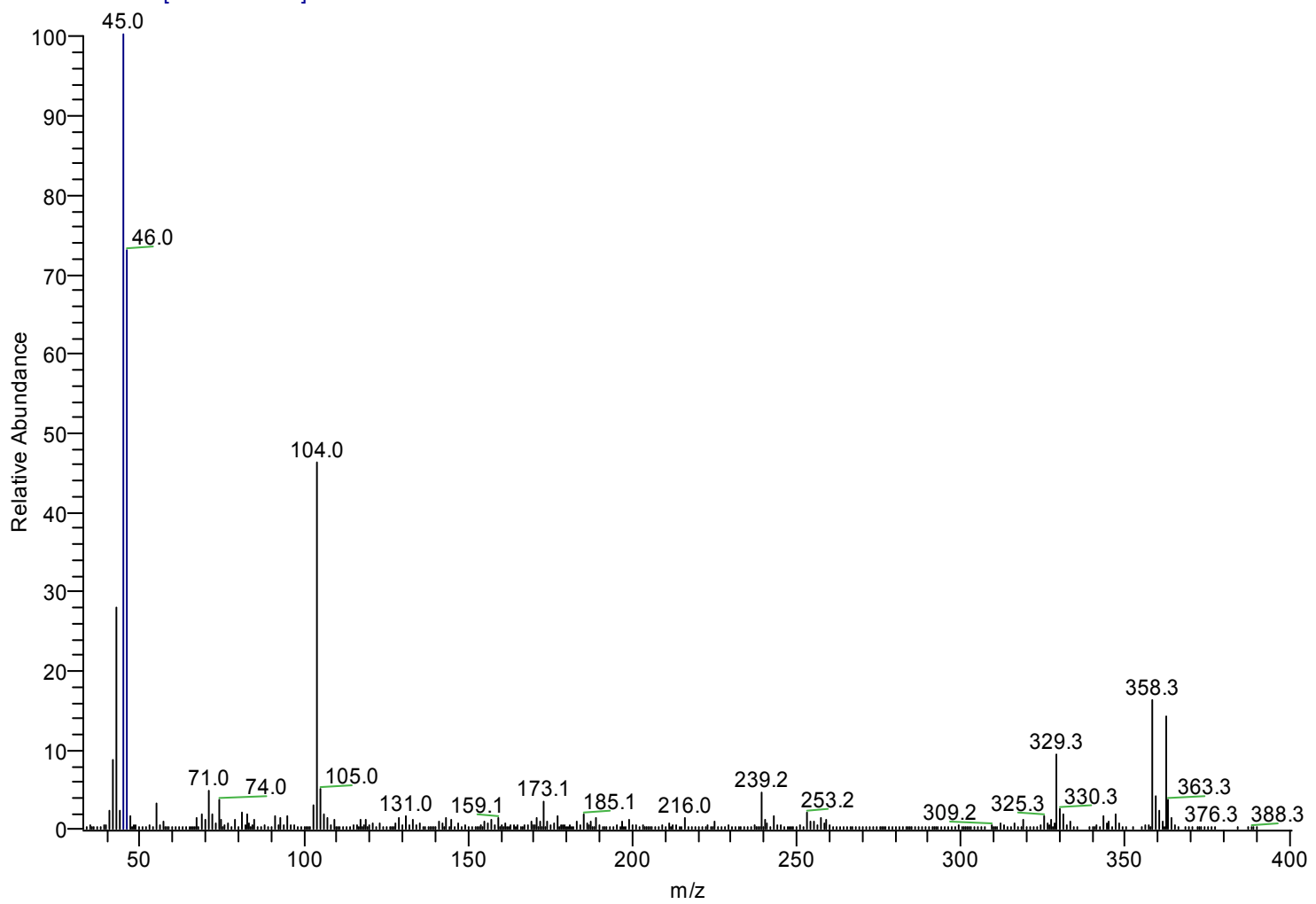




\subsection{Compound 7}

KS-183 \#46 RT: 2.85 AV: 1 NL: $1.67 E 7$

$\mathrm{T}$ : + c El Full ms [ 32.50-390.50]

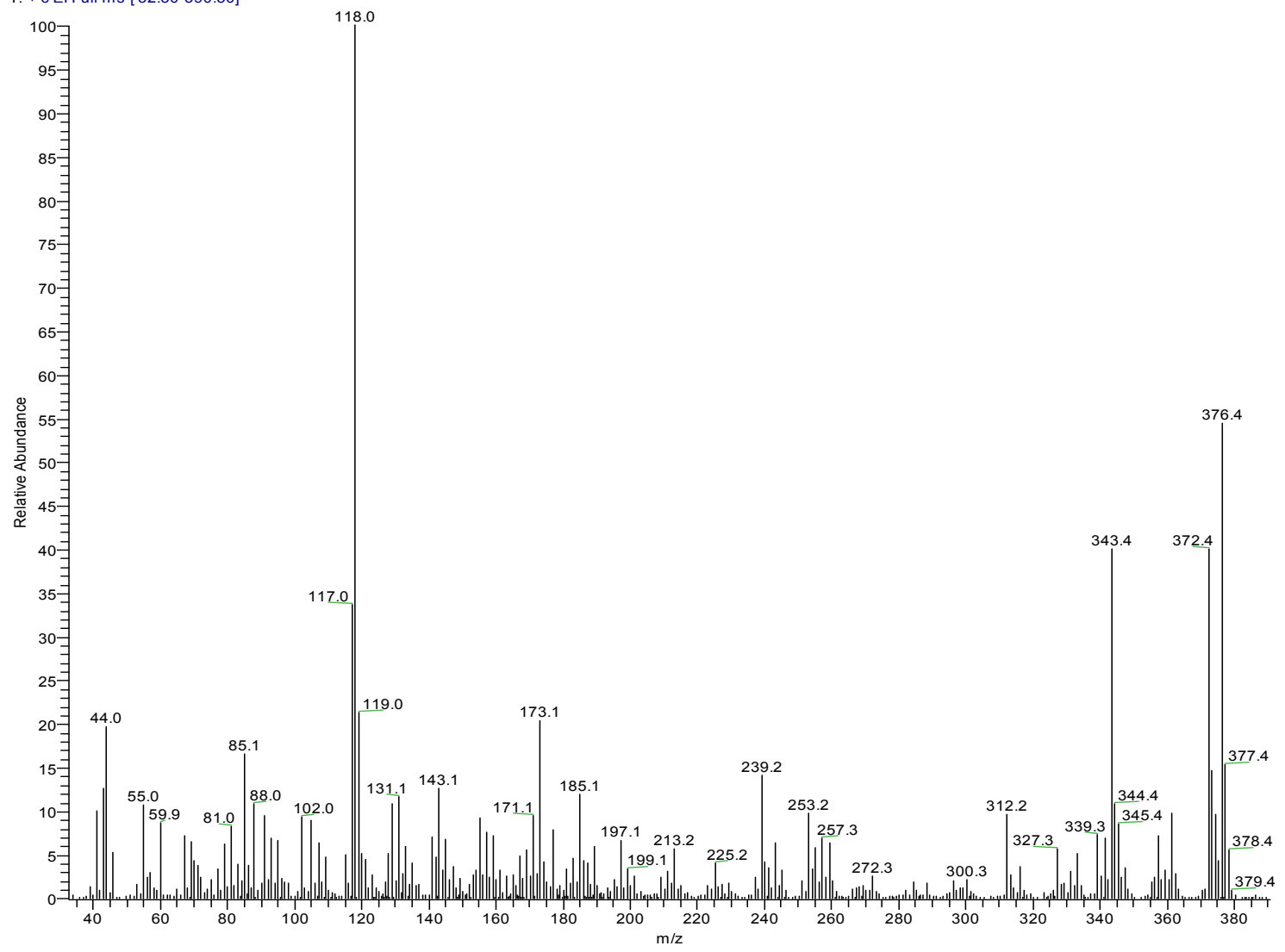

\subsection{Compound 8}

KS-248 \#4 RT: 0.18 AV: 1 NL: $3.47 E 6$

T: + c El Full ms [32.50-400.50]

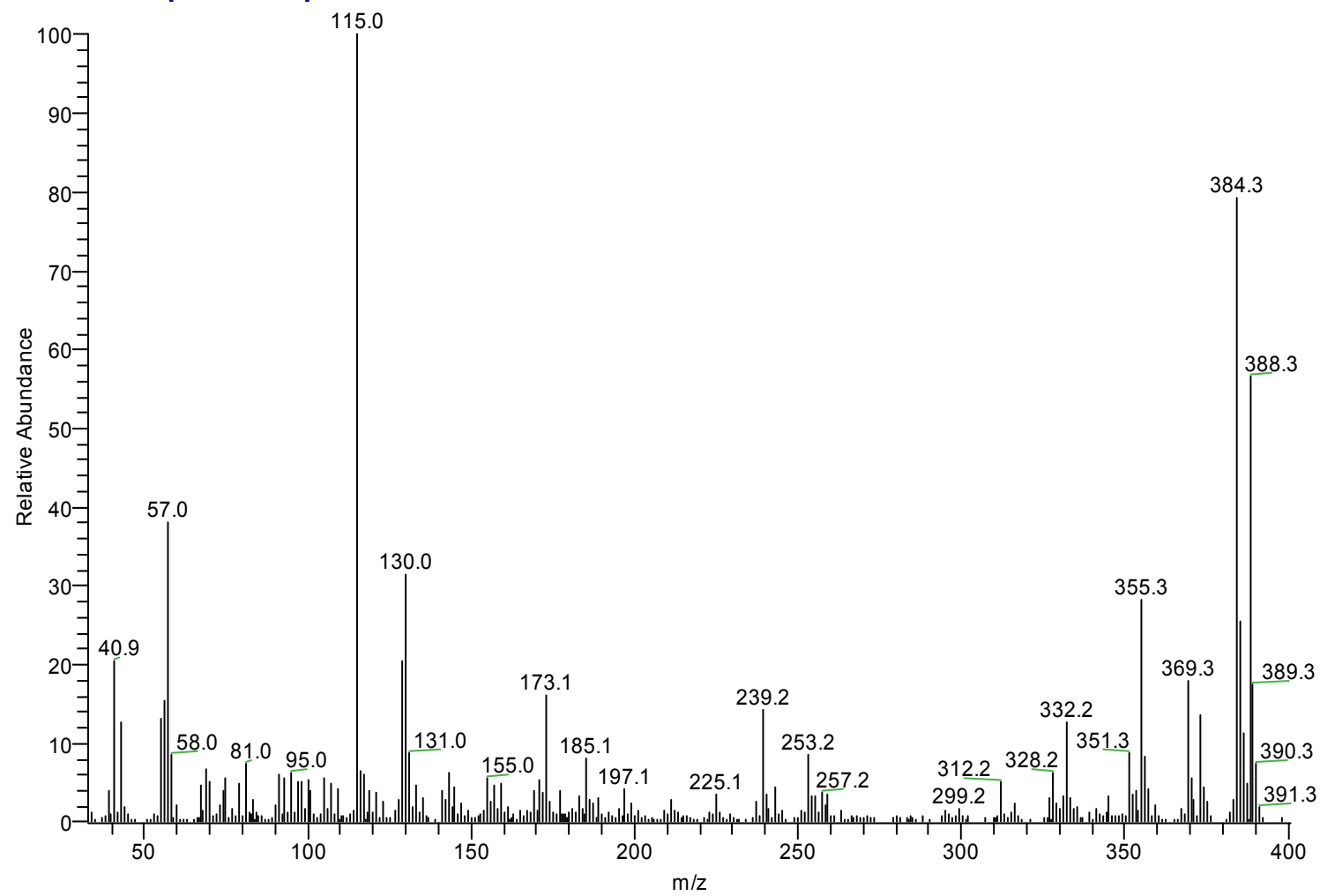




\subsection{Compound 9}

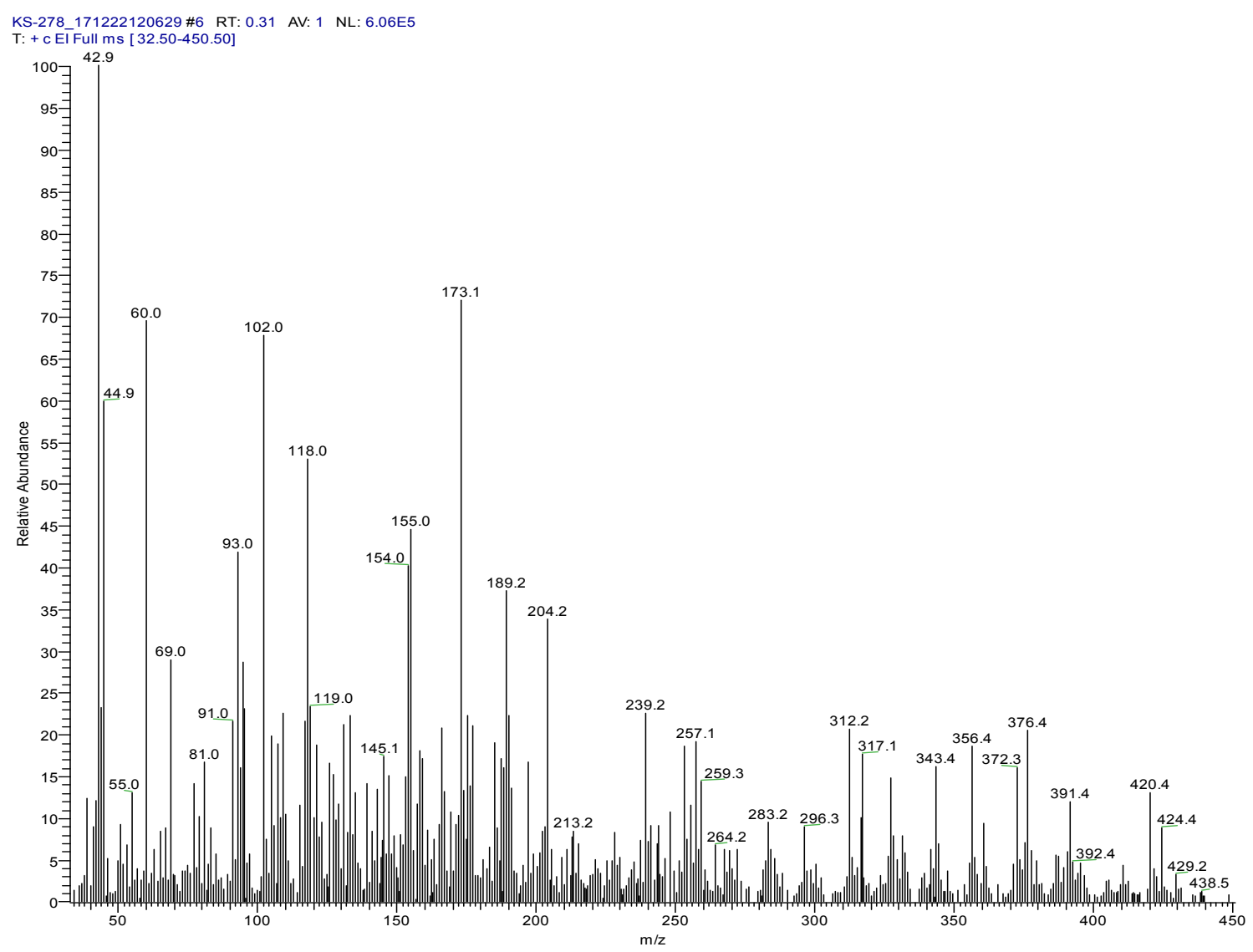

\subsection{Compound 10}

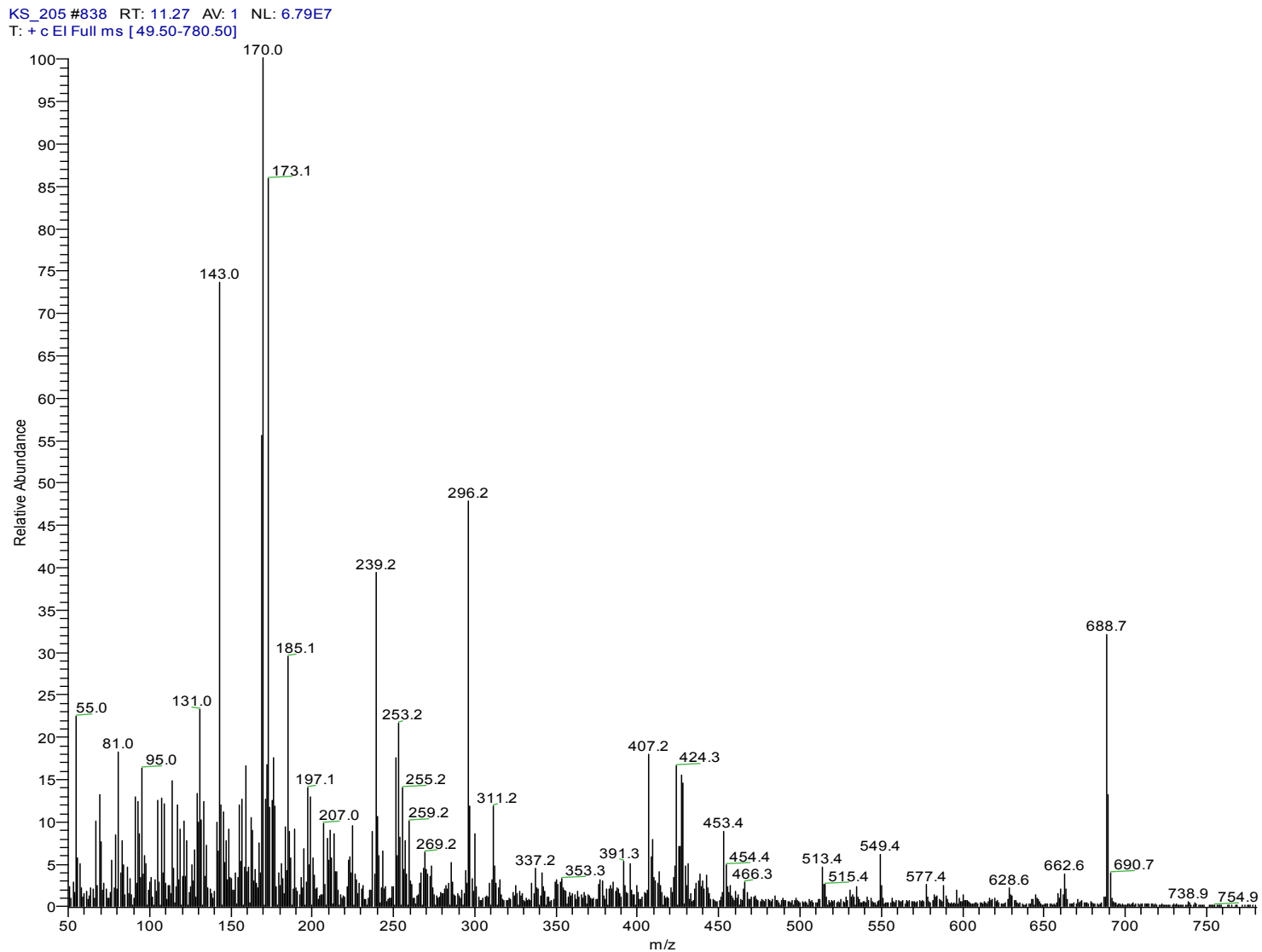


3.11. Compound 11

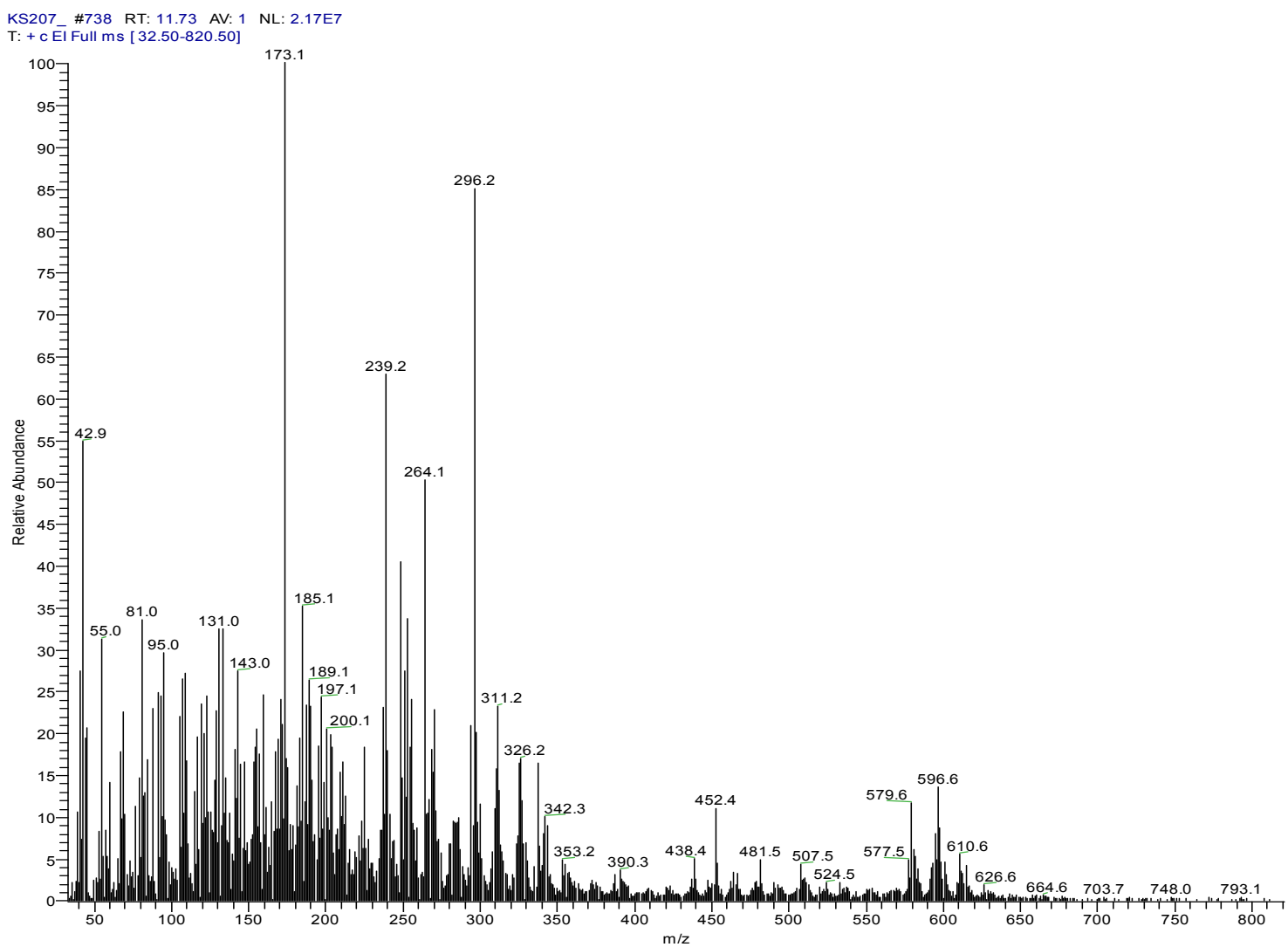

3.12. Compound 12

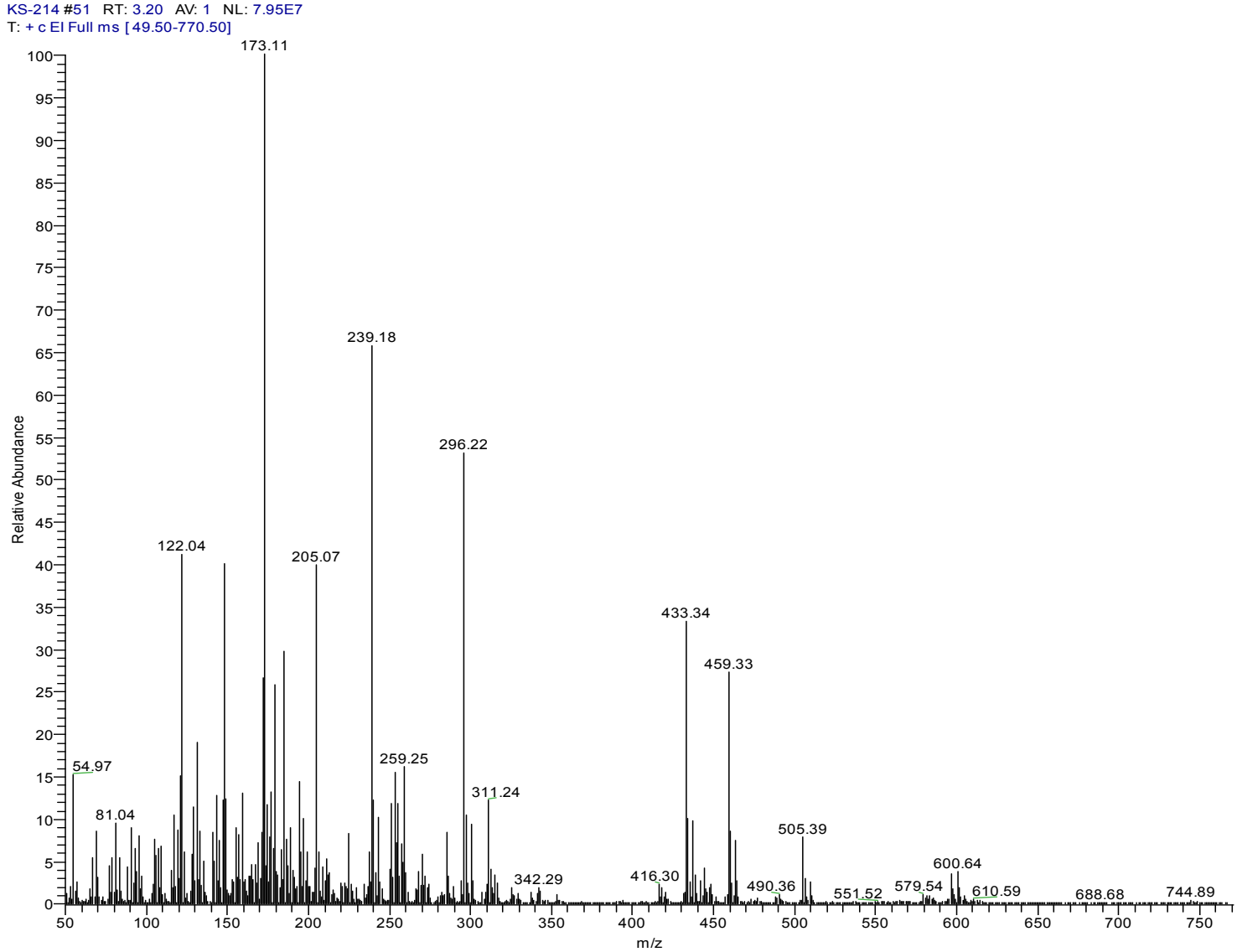

